6-1992

\title{
Shelter Selection By Spiny Lobster Under Variable Predation Risk, Social Conditions, And Shelter Size
}

DB Eggleston

Rom Lipcius

VIMS

Follow this and additional works at: https://scholarworks.wm.edu/vimsarticles

Part of the Marine Biology Commons

\section{Recommended Citation}

Eggleston, DB and Lipcius, Rom, "Shelter Selection By Spiny Lobster Under Variable Predation Risk, Social Conditions, And Shelter Size" (1992). VIMS Articles. 1737.

https://scholarworks.wm.edu/vimsarticles/1737

This Article is brought to you for free and open access by the Virginia Institute of Marine Science at W\&M ScholarWorks. It has been accepted for inclusion in VIMS Articles by an authorized administrator of W\&M ScholarWorks. For more information, please contact scholarworks@wm.edu. 


\title{
SHELTER SELECTION BY SPINY LOBSTER UNDER VARIABLE PREDATION RISK, SOCIAL CONDITIONS, AND SHELTER SIZE ${ }^{1}$
}

\author{
David B. EgGleston ${ }^{2}$ AND Romuald N. Lipcius \\ The College of William and Mary, School of Marine Science, Virginia Institute of Marine Science, \\ Gloucester Point, Virginia 23062 USA and \\ Caribbean Marine Research Center, Lee Stocking Island, Exuma Cays, Bahamas
}

\begin{abstract}
Shelter use patterns of den-dwelling Caribbean spiny lobster, Panulirus argus, appear to be regulated by predation risk. The risk of predation may be modified by (1) social structure, which alters the effectiveness of communal defense, and (2) the scaling between lobster size and shelter size, which enhances the protective capacity of the den. These hypotheses were tested with field enclosure experiments using artificial lobster shelters, which examined the effects of predation risk (i.e., presence or absence of a major predator, the nurse shark Ginglyostoma cirratum), spiny lobster size, social condition (i.e., presence or absence of conspecifics), and shelter size upon den choice by juvenile and adult $P$. argus. To corroborate the findings of the enclosure experiments we also quantified seasonal, size-specific abundance patterns of $P$. argus in the field by deploying artificial lobster shelters (casitas) of different sizes in two habitats that differed primarily in the potential for gregarious interactions: an inner-bay, sand seagrass flat with high lobster densities, and an outer-bay, seagrass bed adjacent to coral reefs with sparsely distributed lobsters.

The experimental and observational field results were strikingly similar-social condition and the scaling of lobster size to shelter size jointly regulated den choice patterns of adult and juvenile Panulirus argus, particularly under high predation risk. When conspecific density and predation risk were low, lobsters resided primarily in shelters whose dimensions were scaled to their own; when conspecific density was high and predation risk was low, lobsters resided predominantly in large shelters offering the highest potential for gregariousness; when conspecific density and predation risk were high, lobsters shifted to gregarious habitation in smaller, scaled shelters; and, when predation risk was high and conspecific density was low, lobsters occupied smaller shelters. The frequency of gregariousness in the field was much higher at the inner-bay site, where lobsters were dense, than at the outerbay site, where lobsters were sparse, even accounting for the difference in lobster density between sites. This study indicates that the density of conspecifics in a given habitat can enhance gregariousness in spiny lobsters, which in turn influences the relative impact of lobster size, shelter size, and predation risk upon den choice. In defining the critical determinants of den choice for $P$. argus, we also provide an empirical and conceptual framework for identifying how variation in the availability of resources, such as conspecifics and appropriately scaled refuges, influence the distribution and abundance of social, shelterdwelling species.

Key words: density-dependent behavior; gregarious behavior; habitat structure; habitat use; Mexican Caribbean; Panulirus argus; predation risk; refuge; shelter use; size scaling; social behavior; spiny lobster.
\end{abstract}

\section{INTRODUCTION}

One of the major ecological issues regarding the distribution and abundance of animals concerns habitat selection and its regulatory factors. Predation affects habitat selection by mobile prey in that individuals at risk must either seek habitats that provide a refuge from predators, or, in social species, cooperate and collectively reduce the risk of predation (e.g., flocks,

\footnotetext{
${ }^{1}$ Manuscript received 6 February 1991; revised 28 August 1991 ; accepted 3 September 1991.

2 Present address: University of Washington, College of Ocean and Fishery Sciences WH-10, Seattle, Washington 98195 USA.
}

schools, herds, troops, or packs). Although predation is considered the major selective force in the evolution of animal social structure, growing evidence indicates that animals can assess and behaviorally modify their risk of predation during their lifetime (Lima and Dill 1990 and references therein). Habitat complexity (sensu Hicks 1986) has also been shown to influence the distribution and abundance of a diverse group of mobile animals (Hacker and Steneck 1990, O’Conner 1991, Schneider and Mann 1991 and references therein). Experimental habitat manipulations demonstrate a positive relationship between prey survival and habitat structural complexity (Crowder and Cooper 1982, Coull and Wells 1983, Shulman 1985, Gotceitas and Colgan 
1989, but see review by Heck and Crowder [1991]). Moreover, the protective capacity of structural refuges varies with prey size, so that some specified scaling offers maximal protection to a sheltering individual (Eggleston et al. 1990). Hence, reduced predation pressure in structurally complex habitats should produce strong, size-specific preferences for these habitats (Huffaker 1958, Smith 1972, Ryer 1988, Hacker and Steneck 1990).

Prey in groups might have different survival rates than solitary dwellers in similar habitats. For example, grouped prey often detect an approaching predator sooner than do solitary individuals, thereby facilitating escape (Siegfried and Underhill 1975, Lazarus 1979, Magurran and Girling 1986, Pitcher et al. 1986). Grouped prey may also defend themselves collectively against predators and sometimes exhibit predator mobbing (Altmann 1974, Curio 1978, Dominey 1983). For species that demonstrate both shelter-seeking and gregarious behavior, shelter preferences and the resultant survival rates may differ not only with shelter features, but also with the individual's body size and group size or behavior. The joint impact of shelter characteristics, body size, and social conditions upon habitat selection has rarely, if ever, been examined experimentally under variable predation risk. We present the results of a series of field experiments and observations that examine how gregarious behavior, lobster size, and shelter size jointly influence den selection in the Caribbean spiny lobster, Panulirus argus Latreille, under variable predation pressure. We consider den choice by spiny lobsters to be an effective model system for examining how predation risk regulates habitat selection by social, shelter-dwelling species under different levels of biotic (e.g., conspecific density) and abiotic (e.g., size-specific shelters) resources, and how these factors interact to affect the distribution and abundance of the species.

For social, shelter-seeking prey such as spiny lobsters, structural refuges of an appropriate size may be a limiting resource in certain habitats (Ford et al. 1988, Eggleston et al. 1990, Phillips 1990). We propose that conspecifics may also be viewed as a limiting resource if low lobster abundance reduces the potential for gregarious interactions and thereby limits the protective capacity of shelters. This view is analogous to the concept that the availability of mates is a habitat-specific limiting resource in certain mating systems (Emlen and Oring 1977). Despite the long-standing recognition that spatial and temporal variation in the availability of resources influences the social structure and survival of mobile prey (see reviews by Wiens 1976, Pulliam and Caraco 1984, Pulliam 1989), little is known of the relative importance of habitat structural complexity vs. sociality in determining the distribution and abundance of prey, particularly under variable predation risk and conspecific density.

Spiny and rock lobsters (Crustacea: Decapoda: Pal- inuridae) are widely distributed, marine benthic omnivores that frequently aggregate during the day in crevices of coral and rocky reefs (Berrill 1975, Herrnkind et al. 1975, Cobb 1981, Zimmer-Faust and Spanier 1987). These shelters provide lobsters greater protection from predators than nearby seagrass beds, with maximal protection occurring when lobsters reside in dens that are scaled according to body size (Eggleston et al. 1990). Predation risk appears to decrease with increasing lobster body size (Smith 1990, Eggleston et al., in press a), and gregarious behavior within dens probably enhances individual survivorship because spiny lobsters collectively use their spinose antennae to fend off diurnally active predators (Berrill 1975, Cobb 1981, Zimmer-Faust and Spanier 1987). At sunset spiny lobsters emerge from their dens to forage nocturnally in nearby habitats such as reef flats and seagrass beds (Herrnkind et al. 1975, MacDonald et al. 1984), though lobsters about to molt remain near their shelters at night to complete the process (Lipcius and Herrnkind 1982). Thus, shelters are required as refuges both day and night.

Obligate crevice dwellers (e.g., spiny lobsters, stomatopods, and certain reef fishes) may face a decline in the availability of crevices as they grow (Steger 1987, Moran and Reaka 1988), potentially creating a population bottleneck (Caddy 1986). One prerequisite to addressing shelter-related population bottlenecks is more detailed knowledge of how sociality influences size-specific shelter choice. For example, if shelter is limiting the abundance of a particular size class of spiny lobster, the addition of appropriately scaled shelters might not alleviate the population bottleneck if lobsters prefer to reside gregariously with conspecifics in large shelters compared to solitary residency in smaller shelters that are scaled according to body size.

Despite the importance of gregarious sheltering and shelter size to spiny lobster survival (Berrill 1975, Eggleston et al. 1990), no information exists on the interactive influence of these factors upon shelter selection. Hence, we have addressed three questions. (1) What are the interactive effects of lobster and shelter size, social condition (i.e., solitary vs. grouped with conspecifics), and predation risk (i.e., presence or absence of a predator), upon den choice by spiny lobsters? (2) Do size-specific abundance patterns of spiny lobster in different-sized shelters vary spatially and temporally between habitats that differ in the abundance of conspecifics? (3) Is there a conceptual framework that predicts den habitation patterns of spiny lobster as a function of spatial and temporal variation in the joint availability of conspecifics and shelter? Such a framework may be applicable to all shelter-seeking, gregarious species that face variable predation intensity. To address these questions we designed field enclosure experiments that examined the effects of the aforementioned factors in the presence or absence of a predator (i.e., the nurse shark Ginglyostoma cirratum Gmelin) 


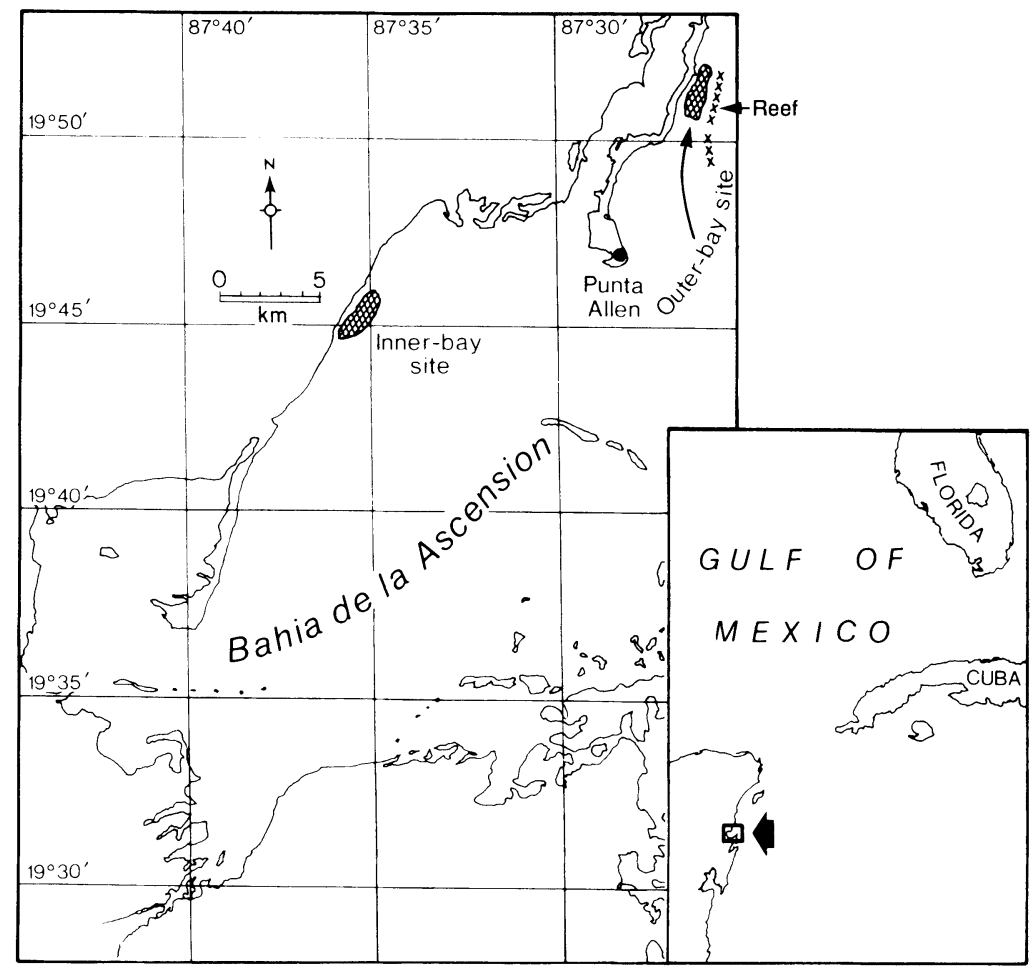

FIG. 1. Study sites at Bahia de la Ascension, Mexico.

upon den choice by juvenile and adult Panulirus argus. Nurse sharks are major predators of spiny lobsters throughout the Caribbean (Cuba: Cruz and Brito 1986; Mexico: Eggleston et al., in press $b$; Florida: Smith 1990). We also attempted to corroborate the enclosure results by quantifying seasonal size-specific abundance patterns of $P$. argus in the field by deploying artificial lobster shelters of different sizes in two habitats with contrasting spiny lobster population structure.

\section{MethodS AND MATERIALS Field sites}

Field observations and enclosure experiments were conducted in Bahia de la Ascension, a large bay $(\approx 740$ $\mathrm{km}^{2}$ ) within the Sian Ka'an Biosphere Reserve, Mexico $\left(19^{\circ} 45^{\prime} \mathrm{N}, 87^{\circ} 29^{\prime} \mathrm{W}\right.$; Fig. 1). This bay is a productive nursery for juvenile Panulirus argus and supports a commercial fishery for large juveniles and adults (Miller 1989). Two experimental sites with contrasting habitats and spiny lobster population structure were chosen to assess relative patterns of den habitation: an inner-bay, sand-seagrass flat located at the northwestern portion of the bay, and an outer-bay, seagrass (Thalassia testudinum) meadow adjacent to a coral reef (Fig. 1). The inner-bay site is inhabited by juvenile $P$. argus at high densities $(\bar{X} \pm 1 \mathrm{SD}=8.9 \pm 9.0$ lobsters per casita [an artificial lobster shelter, see below], $N=$ 24 casitas) and ranging in size from 15.2 to $108.1 \mathrm{~mm}$ carapace length $(C L$; as measured from the anterior margin of the carapace between the rostral horns to the posterior dorsal margin of the cephalothorax) (59.5 \pm $17.1 \mathrm{~mm} \mathrm{CL}, N=214$ lobsters). The outer-bay site is sparsely inhabited by large juveniles and adults (1.2 \pm 1.3 lobsters per casita, $N=24$ casitas), ranging in size from 40.0 to $120.0 \mathrm{~mm} \mathrm{CL}(74.8 \pm 16.5 \mathrm{~mm} \mathrm{CL}, N$ $=29$ lobsters). Both sites are devoid of rocky outcrops and crevices that might serve as natural lobster dens, though natural reefs at a distance of $60 \mathrm{~m}$ from the outer-bay site may serve as shelters. Moreover, previous field experiments showed no differences in predation rates on juvenile $P$. argus between the sites (Eggleston et al. 1990). Hence, a key difference between our experimental sites was the enhanced potential for gregarious interactions at the inner-bay site relative to the outer-bay site, due to the higher abundance of conspecifics at the inner-bay site.

\section{Artificial lobster shelters}

Our design of artificial lobster shelters was based on "casitas"-sunken wood and concrete structures that simulate lobster dens (Miller 1989) (Fig. 2), and are used to concentrate lobsters for harvest in Cuba and the Mexican Caribbean (Cruz and Brito 1986, Miller 1989). We constructed three casita sizes: small (132.3 $\mathrm{cm}$ length $\times 88.4 \mathrm{~cm}$ width $\times 1.9 \mathrm{~cm}$ height of opening), medium $(157.3 \times 105.1 \times 3.8 \mathrm{~cm})$, and large $(177 \times$ $118 \times 6 \mathrm{~cm})$, which were scaled to small $(35-45 \mathrm{~mm}$ $\mathrm{CL})$, medium $46-55 \mathrm{~mm} \mathrm{CL})$, and large $(65-80 \mathrm{~mm}$ 


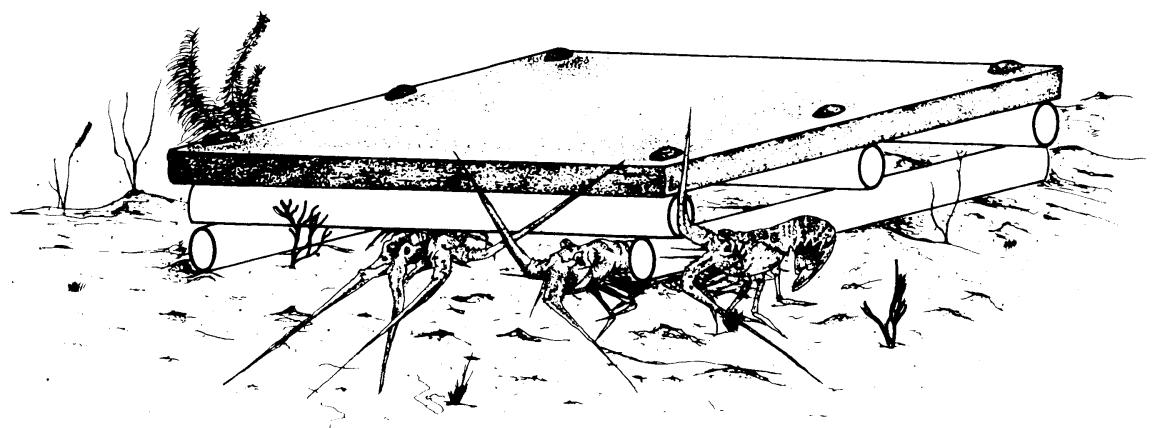

FIG. 2. A large casita (artificial lobster shelter) constructed with a frame of PVC (polyvinyl chloride plastic) pipe and roof of cement $(177 \mathrm{~cm}$ length $\times 118 \mathrm{~cm}$ width $\times 6 \mathrm{~cm}$ height of opening).

CL) lobsters, respectively. Shelters were constructed with a reinforced concrete roof bolted to a supporting polyvinyl chloride plastic (PVC) pipe frame. The scaling procedure is detailed in Eggleston et al. (1990). Reductions in casita opening height allowed entry of the targeted lobster size class, and also excluded larger predators. The burrowing ability of most panulirid lobsters is assumed to be minimal (Kanciruk 1980), and $P$. argus is unable to modify the opening height of the casitas (Fig. 2). Several physical properties of the casita appear to make it an optimal lobster den: (1) shaded cover provided by the wide concrete roof; (2) a low ceiling that excludes large piscine predators; and (3) multiple den openings that are smaller than the inner roof height of the casita (Fig. 2) (Eggleston et al. 1990). The use of casitas scaled according to lobster size permitted us to standardize den size and availability in different habitats.

\section{Enclosure experiments}

Den choice by solitary and grouped lobsters was examined in three circular field enclosures located $10 \mathrm{~m}$ apart on a shallow sand flat off Punta Allen, Mexico (Fig. 1). Enclosures were $6 \mathrm{~m}$ in diameter, $1.4 \mathrm{~m}$ tall and constructed of $1.3-\mathrm{cm}$ mesh hardware cloth supported by wooden posts inserted into the sediment. One each of the large, medium, and small casitas was placed concentrically within each enclosure (Fig. 3). Water depth within the enclosures averaged $1.2 \mathrm{~m}$, temperature $30^{\circ}-32^{\circ} \mathrm{C}$, and salinity $34-36 \mathrm{mg} / \mathrm{kg}$.

Shelter choice experiments were performed within the field enclosures from 2 July to 15 August 1989. Spiny lobsters collected from existing casitas were held in traps $1-2 \mathrm{~d}$ prior to each experiment; only male intermolt lobsters exhibiting strong "tail flipping" responses were used in our experiments. Lobsters were classified as small (35-45 $\mathrm{mm} \mathrm{CL})$, medium (46-56 $\mathrm{mm} \mathrm{CL}$ ), and large ( $70-80 \mathrm{~mm} \mathrm{CL}$ ). Small and medium lobsters could inhabit all three casita sizes, whereas large lobsters could only fit into medium and large casitas. Individual lobsters were identified by a small, plastic-numbered tag attached to the base of one antenna with a plastic cable-tie. The tag ensured that an individual lobster could be readily identified under any casita. Tagged lobsters were placed in the center of the enclosure between 1700 and 1800 . Final residency was recorded the following morning at sunrise (0800-0900); lobsters remained under the same casita throughout the day.

We used scuba and circular nets $(4 \mathrm{~m}$ diameter $\times 1$ $\mathrm{m}$ height $\times 2.5-\mathrm{cm}$ mesh) to capture female nurse sharks (Ginglyostoma cirratum; $\bar{X} \pm 1 \mathrm{SD}=138 \pm 7 \mathrm{~cm}$ fork length), either from large casitas or patch reefs. Sharks

\section{Experimental Design}
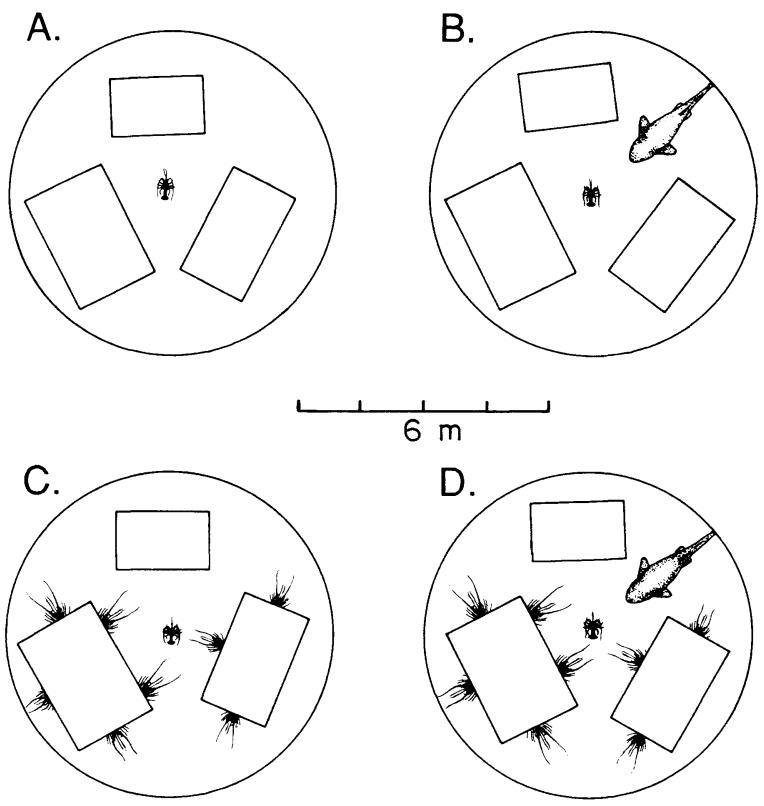

FIG. 3. Schematic representation of experimental design for the enclosure experiments. (A) solitary small (carapace length [CL] 35-45 mm), medium (46-55 mm CL) or large (70-80 mm CL) lobster, (B) solitary small or medium lobster plus a nurse shark predator, (C) small or medium lobster grouped with either eight medium or eight large conspecifics, and (D) small or medium lobster grouped with either eight medium or eight large conspecifics plus a nurse shark predator. 
TABLE 1. Treatment combinations (see Fig. 3) in the enclosure experiment. Experimental lobsters were either solitary or placed individually in an enclosure with a group of medium- or large-sized lobsters. ${ }^{*}=$ treatment combination used; $\cdots$ $=$ treatment combination not used; $\mathrm{NA}=$ not applicable.

\begin{tabular}{|c|c|c|c|c|c|}
\hline \multirow[b]{2}{*}{ Predator } & \multirow[b]{2}{*}{ Grouping } & \multirow[b]{2}{*}{ Lobster size in group } & \multicolumn{3}{|c|}{ Experimental lobster size } \\
\hline & & & Small & Medium & Large \\
\hline Absent & $\begin{array}{l}\text { Solitary } \\
\text { Grouped }\end{array}$ & $\begin{array}{l}\text { NA } \\
\text { Medium-sized } \\
\text { Large-sized }\end{array}$ & $\begin{array}{l}* \\
* \\
*\end{array}$ & $\begin{array}{c}* \\
\cdots \\
*\end{array}$ & $\begin{array}{c}* \\
\cdots \\
\cdots\end{array}$ \\
\hline Present & $\begin{array}{l}\text { Solitary } \\
\text { Grouped }\end{array}$ & $\begin{array}{l}\text { NA } \\
\text { Medium-sized } \\
\text { Large-sized }\end{array}$ & $\begin{array}{l}* \\
* \\
*\end{array}$ & $\begin{array}{c}* \\
\cdots \\
*\end{array}$ & $\begin{array}{l}\cdots \\
\cdots \\
\cdots\end{array}$ \\
\hline
\end{tabular}

were held in field enclosures and fed twice daily with $\approx 350 \mathrm{~g}$ of diced reef fish (typically grunts, family Pomadasyidae).

In the enclosure experiment either solitary experimental lobsters or single experimental lobsters grouped with eight other lobsters of a particular size class were placed in the enclosures (Fig. 3). In some treatments, lobsters were enclosed with a non-feeding nurse shark, yielding 11 treatment combinations (Table 1, Fig. 3). Each treatment was replicated six to nine times and systematically interspersed (i.e., performed at different times) throughout the experimental period. Individual experimental lobsters were exposed to each treatment combination only once, to ensure independence of experimental trials. Our use of up to nine lobsters per enclosure was based on the mean number of lobsters per casita recorded at the inner-bay site ( 8.9 lobsters per casita, see Field sites, above).

Statistical analyses were conducted on frequencies of experimental lobsters within each casita size (loglikelihood analysis: $G$ test, Sokal and Rohlf 1981). In all cases, individual values in the contingency tables were independent because they represented single values from an individual lobster in a trial. We employed four separate, pre-planned multi-way log-likelihood analyses on three different combinations of the treatments (Table 1, Fig. 3) as follows:

1. Solitary lobsters. - To determine how den choice by solitary lobsters varied with lobster and shelter size, we employed two separate, two-way log-likelihood models with the following treatment combinations: (a) lobster size (medium and large), and casita size (medium and large), and (b) lobster size (small and medium), and casita size (small, medium, and large). We eliminated the small casita level from planned comparisons involving large lobsters because large lobsters could not enter small shelters. Moreover, we did not test statistically between den choice patterns of small and large lobsters because of the non-orthogonal, unequal design (i.e., small lobsters in small, medium, and large casitas vs. large lobsters in medium and large casitas).

2. Small lobsters. - To examine the interactive effects of shelter size, social condition, average size of grouped conspecifics, and presence of a predator upon den choice by small juvenile spiny lobsters, we employed a three-way log-likelihood model with social condition (solitary vs. grouped with 8 large lobsters vs. grouped with 8 medium lobsters), presence or absence of a predator, and casita size (small, medium, and large) as factors.

3. Medium lobsters. - To assess the interactive effects of shelter size, social condition, and presence of a predator upon den choice by medium juvenile spiny lobsters, we employed a three-way log-likelihood model with social condition (solitary vs. grouped with 8 large lobsters), presence or absence of a predator, and casita size (small, medium, and large) as factors. These results were then contrasted with those for small lobsters.

4. Size within a group.-Groups of lobsters within a particular trial were not independent across trials, precluding the use of the $G$ test. Hence, we determined the interactive effects of size within a group of lobsters and presence of a predator upon lobster proportional occupancy in large casitas with a two-way, fixed-factor ANOVA model with lobster size (medium and large) and presence or absence of a predator as factors. Proportional occupancy (angular transformed) was calculated as the number of lobsters residing under a large casita divided by the total number of lobsters in the trial. We assumed that the addition of either a single small or medium lobster to the grouped treatment would not influence den choices by the group.

\section{Field observations}

Size-specific lobster abundance in casitas was quantified at the inner-bay and outer-bay sites on five separate occasions from 6 January 1989 to 20 June 1990. At the inner-bay site, we positioned a row of six large casitas during July 1988 (Fig. 4). Each large casita had one medium and one small casita placed $10 \mathrm{~m}$ away, yielding six stations with one small, one medium, and one large casita arranged in a triangle (Fig. 4). At the outer-bay site, we positioned six small, medium, and large casitas equidistant between the shore and reef line during August 1988, and arranged these in two rows, each containing three triangular stations (Fig. 4). 
Inner-bay site
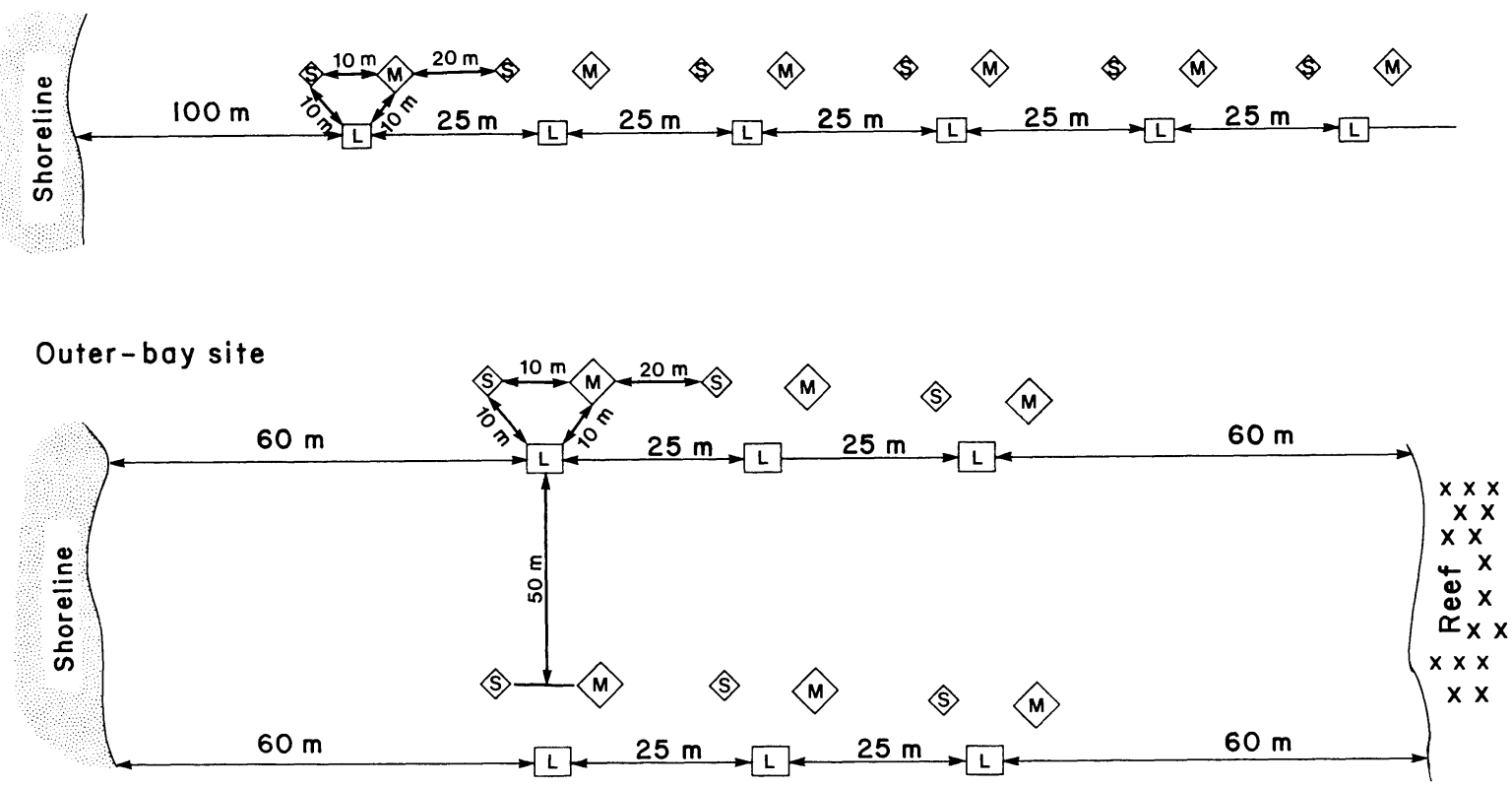

FIG. 4. Schematic representation of casita (artificial lobster shelter) layout at the inner-bay and outer-bay sites. S $=$ small, $\mathrm{M}=$ medium, and $\mathrm{L}=$ large casitas.

We recorded the abundance and sizes of spiny lobsters residing under casitas at both sites during winter (January 1989), spring (April 1989), summer (twice: July 1989 and June 1990), and fall (October 1989). Using scuba, we captured lobsters with a tail snare or by surrounding the casita with a circular net ( $4 \mathrm{~m}$ diameter $\times 1 \mathrm{~m}$ height $\times 2.5-\mathrm{cm}$ mesh) and herding the lobsters into the conical end of the net with PVC pipes. Lobsters were then measured (to nearest $0.1 \mathrm{~mm} \mathrm{CL}$ ), tagged, and released.

Lobster abundance in each of the three casita sizes was compared between the inner-bay and outer-bay sites over time with a three-way repeated-measures ANOVA model (Winer 1971); time was the repeated measure (January 1989, April 1989, July 1989, October 1989, and June 1990), while casita size and site were factors. Time was introduced into the analysis to account for temporal differences in lobster migration and shelter use patterns due to seasonal variation or the potential positive (increased food) or negative (increased predators and competitors) effects subsequent to floral and faunal colonization of the casitas. We then used separate multi-way repeated-measures ANOVA models to examine how lobster abundance of each of the three lobster size classes (small, medium, and large) varied as a function of casita size at both sites over time. Numbers were log-transformed when necessary to meet assumptions of normality and homogeneity of variance (Underwood 1981).

Mean lobster size could not be analyzed with a repeated-measures ANOVA model similar to that em- ployed for abundance data because there were insufficient error degrees of freedom due to the large number of uninhabited casitas (see Table 6). Thus, we assumed that lobsters were not segregating themselves by size among casita stations (i.e., a triangular station of one large, one medium, and one small casita), and proceeded to analyze mean lobster size within a particular casita as a function of site, casita size (small, medium, large), and time with a three-way fixed-factor ANOVA model. In this case the variances remained heteroscedastic (Cochran's $C$ test) despite several transformations (e.g., logarithm and square root). Hence, hypotheses regarding lobster size were rejected at alpha values lower than the $P$ values of the test for homogeneity of variance (Underwood 1981). Means were contrasted with the Ryan's $Q$ multiple comparison test (Einot and Gabriel 1975), as recommended by Day and Quinn (1989).

To verify the relationship between lobster and shelter size, as indicated from the previous analysis (see Results: Field observations: Lobster to shelter size relationships), we eliminated time and site as factors and contrasted mean lobster size ( $\mathrm{mm} \mathrm{CL}$ ) between two different-sized casitas within the same casita station using a series of paired-comparison tests. We then tested whether casita use by lobsters was uniform, random, or aggregated (gregarious) with the two-tailed Poisson model (Zar 1984). Gregarious habitation within particular casitas could then be identified as those casitas containing significantly more lobsters than the mean number of lobsters per casita per sampling date. Small 


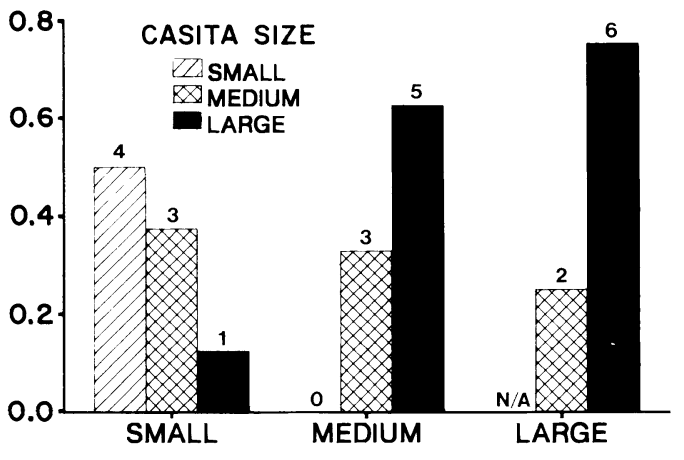

LOBSTER SIZE

FIG. 5. Den choice in enclosure experiments with solitary spiny lobsters (Panulirus argus) comparing proportional occupancy in three casita (artificial lobster shelter) sizes as a function of lobster size (small: $35-45 \mathrm{~mm}$ carapace length [CL], medium: 46-55 mm CL, large: 70-80 mm CL). Numbers above each histogram bar indicate the number of times lobsters chose a particular casita size. N/A indicates that a lobster size class was physically unable to enter that particular casita size.

casitas were eliminated from this analysis because of low sample sizes (i.e., only 9 out of 30 small casitas contained one or more lobsters).

\section{RESULTS}

\section{Behavioral observations}

The daily diet of reef fish apparently satiated the nurse sharks, since no lobsters were eaten in experimental trials. However, nurse sharks continued to dis-

TABLE 2. Effects of social condition (lobsters solitary, grouped with eight medium lobsters, or grouped with eight large lobsters) and predation risk (predator presence or absence) upon den choice by small lobsters among small, medium, and large casitas (artificial lobster shelters).

(a) Log-likelihood analysis ( $G$ test)

\begin{tabular}{lcc}
\multicolumn{1}{c}{ Source of variation } & df & $G$ \\
\hline Social condition & 4 & $10.38^{*}$ \\
Predation risk & 2 & $3.73 \mathrm{NS}$ \\
Social condition $\times$ Predation risk & 4 & $11.59^{*}$
\end{tabular}

play predatory behavior, as evidenced by their consumption of pre-molt lobsters that were accidently introduced into the enclosures on four separate occasions. The sharks would typically reside under the large casita during the day and swim along the periphery of the enclosure from dusk to dawn. Each large casita was functionally split into two halves beneath the roof by a PVC cross piece, thereby allowing lobsters to cohabit with the nurse shark in the large casitas. Sharks were unable to enter medium or small casitas. Lobsters chose casitas at dawn after nightly forays in the open areas between casitas, but before the shark entered the large casita. Although lobsters that selected the large casita remained there even after the shark entered the casita, they shifted their position such that the shark occupied half of the casita and the lobsters occupied the remaining half. Usually lobsters closest to the shark within the large casita maintained physical contact (using one of the spinose antenna) with the shark throughout the day. This phenomenon was also observed in large, unenclosed casitas in the field.

\section{Enclosure experiments}

Solitary lobsters. - Den choice patterns of solitary lobsters differed significantly by lobster size (Fig. 5). Den choice of small lobsters was significantly different than that of medium lobsters ( $G$ test; $G=8.46, \mathrm{df}=$ $2, P<.05)$; small lobsters occurred primarily in small or medium casitas, whereas medium lobsters chose large and medium casitas and never occurred in small casitas (Fig. 5). Large and medium lobsters did not differ in their den choice patterns ( $G$ test; $G=0.29$, df $=1, P>.05)$; both lobster size classes resided primarily in large casitas (Fig. 5). Thus, large and medium solitary lobsters exhibited similar patterns in den choice by choosing large and then medium casitas, whereas small solitary lobsters chose small and medium casitas over large casitas (Fig. 5).

Small lobsters. - Social condition (i.e., solitary vs. grouped with eight medium lobsters vs. grouped with eight large lobsters) and the presence of a predator

(b) Paired comparisons for the social condition $\times$ predation risk interaction effect. Significance levels were set at an experimentwise error rate of .05 . Treatment levels that are not significantly different at the .05 level share an underline.

Interaction

\begin{tabular}{clll}
\hline \multicolumn{1}{c}{ Predator } & \multicolumn{2}{c}{ Social condition } \\
\hline $\begin{array}{l}\text { Absent } \\
\text { Present }\end{array}$ & Solitary & Grouped with 8 large & Grouped with 8 medium \\
Solitary & Grouped with 8 medium & Grouped with 8 large \\
\hline $\begin{array}{l}\text { Solitary } \\
\text { Grouped with 8 medium lobsters } \\
\text { Grouped with 8 large lobsters }\end{array}$ & $\underline{\text { Absent }}$ & Predator \\
\hline Absent & $\underline{\text { Present }}$ \\
\hline
\end{tabular}

$* P \leq .05$, NS $P>.05$. 
(a) Small Lobster-Solitary

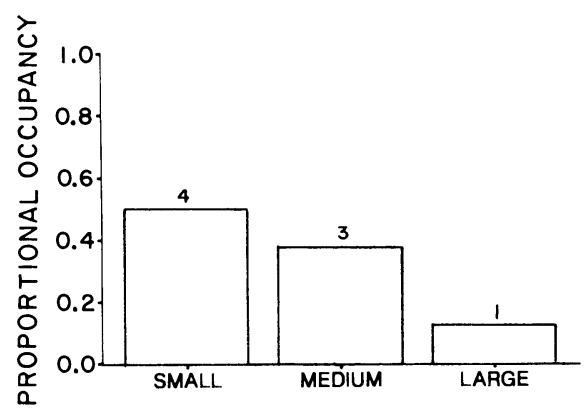

(c) Small Lobster-Grouped

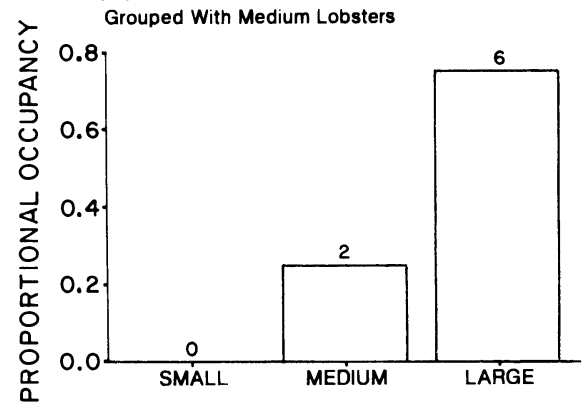

(e) Small Lobster-Grouped

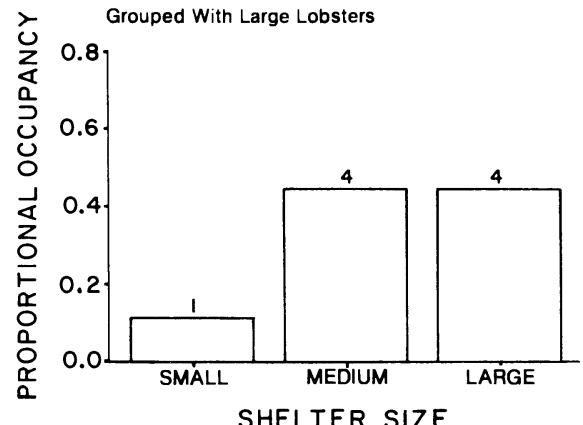

(b) Small Lobster-Solitary + Predator

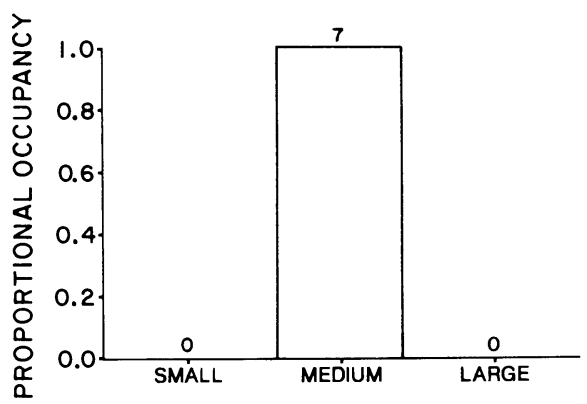

(d) Small Lobster-Grouped + Predator

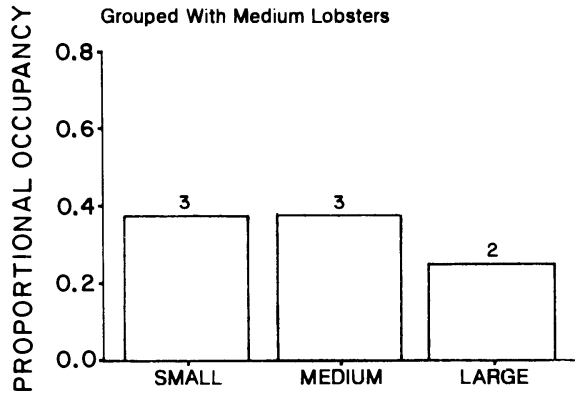

(f) Small Lobster-Grouped + Predator Grouped With Large Lobsters

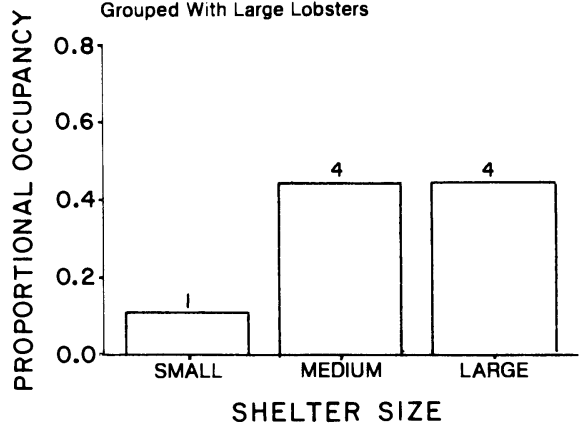

FIG. 6. Den choice in enclosure experiments with small (carapace length: $35-45 \mathrm{~mm}$ ) lobsters (Panulirus argus), comparing proportional occupancy in three casita (artificial lobster shelter) sizes as a function of social condition (solitary vs. grouped with eight medium conspecifics vs. grouped with eight large conspecifics) and presence or absence of a predator. Numbers above each histogram bar indicate the number of times lobsters chose a particular casita size.

jointly affected den choices of small lobsters (Fig. 6, Table 2a). A significant interaction effect between social condition and predation risk precluded generalized conclusions about the main effects (Table 2a) (Underwood 1981). The interaction effect was mainly due to differences in the responses of small lobsters to the presence of a predator under different social conditions (Table 2b). There was no effect of lobster size within a group of lobsters upon den choices by small lobsters under all conditions (Table $2 b$ ). Hence, further discussion of the grouped social condition refers to both medium and large lobsters within a group.

In the absence of a predator, solitary lobsters chose small and medium casitas in preference to medium and large casitas, whereas those grouped with larger conspecifics chose medium and large casitas (compare Figs. 6a, 6c, and 6e). Thus, when predators were absent, small lobsters grouped with conspecifics tended to reside gregariously with conspecifics in larger casitas, rather than in shelters scaled according to body size.

Den choices by solitary lobsters differed significantly in the presence of a predator (Table $2 b$ ). Den choices shifted from $50 \%$ in small casitas, $38 \%$ in medium casitas and $12 \%$ in large casitas in the absence of a predator, to $100 \%$ in medium casitas in the presence of a predator (compare Figs. 6a and 6b). Moreover, in the presence of a predator, den choices by small solitary lobsters were significantly different than those of lob- 
(a) Medium Lobster-Solitary

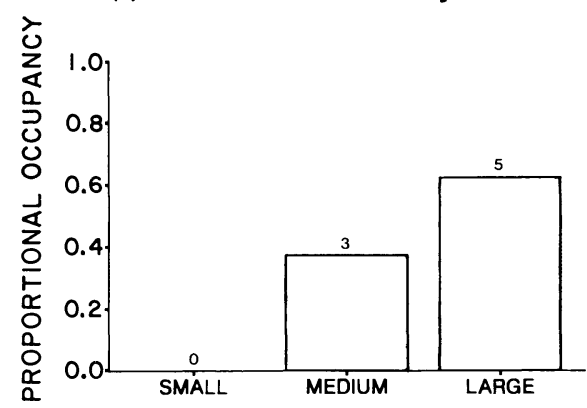

(c) Medium Lobster-Grouped

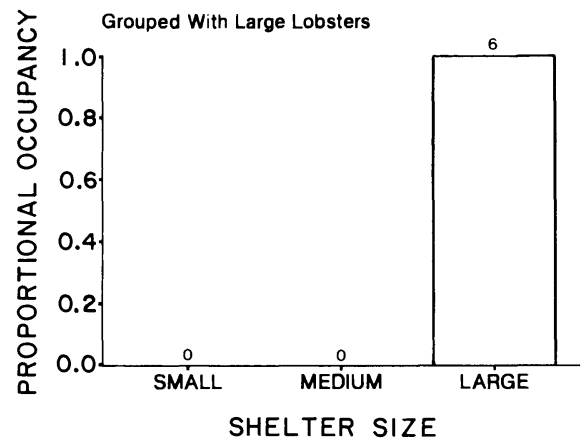

(b) Medium Lobster-Solitary + Predator

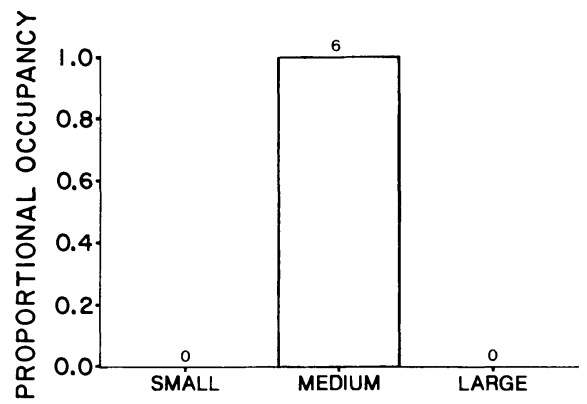

(d) Medium Lobster-Grouped + Predator

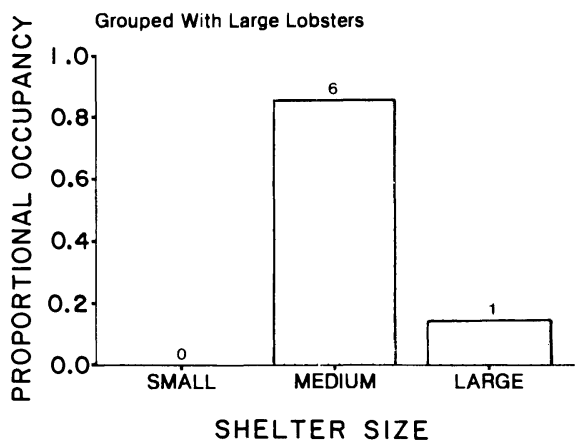

FIG. 7. Den choice in enclosure experiments with medium (carapace length: 46-55 mm) lobsters (Panulirus argus), comparing proportional occupancy in three casita (artificial lobster shelter) sizes as a function of social condition (solitary vs. grouped with eight large conspecifics) and presence or absence of a predator. Numbers above each histogram bar indicate the number of times lobsters chose a particular casita size.

sters grouped with conspecifics (Table $2 b$ ). Den choices by solitary lobsters shifted from $100 \%$ in the medium casita, to $25 \%$ and $44 \%$ in large casitas in the presence of eight medium and eight large lobsters, respectively (compare Figs. 6b, 6d, and 6f). Thus, under high predation risk, den choice by small grouped lobsters appears to have been regulated by a combination of social condition and shelter size. Irrespective of predation risk, solitary lobsters primarily resided in small and medium shelters, whereas grouped lobsters principally used medium and large shelters.

Medium lobsters. - The presence of a predator significantly affected den choices by medium lobsters $(G$ test; $G=19.39$, df $=2, P<.0001$ ), whereas social condition did not ( $G$ test; $G=4.80, \mathrm{df}=2, P=.09$ ) (Fig. 7). The predator $\times$ social condition interaction effect was not significant ( $G$ test; $G=0.47$, df $=1, P$ $=.49$ ). Den choices shifted from $63 \%-100 \%$ in large casitas in the absence of a predator (compare Figs. 7a and $7 \mathrm{c}$ ), to $86 \%-100 \%$ in medium casitas in the presence of a predator (compare Figs. $7 \mathrm{~b}$ and $7 \mathrm{~d}$ ). Thus, under high predation risk, den choices by medium lobsters appeared to be regulated primarily by shelter size rather than social condition, although medium shelters also offered the opportunity for gregariousness. Though the pattern was not significant, grouped medium lob- sters in the absence of a predator shifted to use of large shelters when compared with solitary lobsters (compare Figs. $7 \mathrm{a}$ and $7 \mathrm{c}$ ), similar to the significant pattern observed in small lobsters.

Size within a group. - Proportional occupancy of medium and large sized groups of lobsters in casitas was not significantly different (ANOVA: $F=0.32$, df $=1, P=.57$ ). Although groups of lobsters shifted from larger to smaller shelters in the presence of a predator (compare Figs. $8 \mathrm{a}$ and $8 \mathrm{c}$ with $8 \mathrm{~b}$ and $8 \mathrm{~d}$ ), the trend was not significant (ANOVA; $F=3.44$, $\mathrm{df}=1, P=$ $.08)$; the interaction was also not significant $(F=0.22$, $\mathrm{df}=1, P=.64$ ). A subsequent power analysis (see Zar 1984 , p. 227) indicated that there was inadequate statistical power to detect a predator effect (power $=\mathrm{ca}$ 0.33 ). Thus, we cannot rule out the possibility of a weak predator effect whereby groups of medium and large lobsters shift den choices to smaller shelters, which simultaneously offer the opportunity for gregarious behavior and exclude large predators.

\section{Field observations}

Distribution and abundance. - A total of 421 lobsters was censused during the study, with $82 \%$ (344 lobsters) residing in casitas at the inner-bay site and 18\% (77 lobsters) at the outer-bay site (Table 3). Sampling fre- 
(a) Group of Medium Lobsters

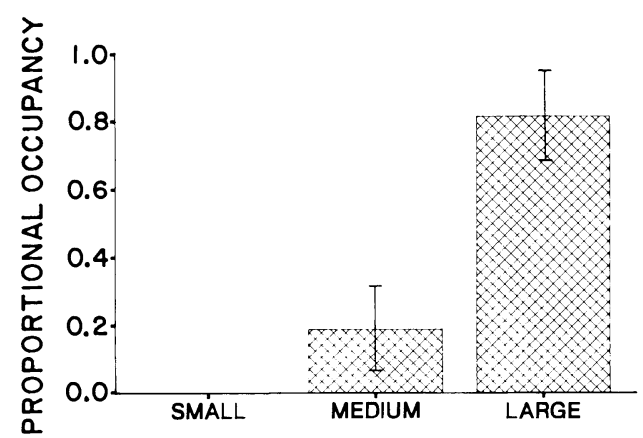

(c) Group of Large Lobsters

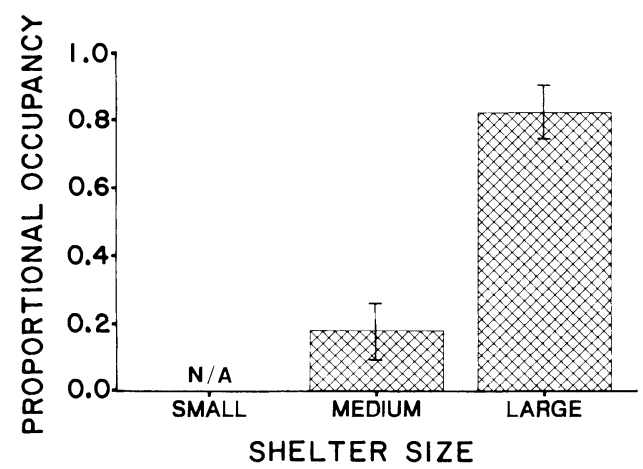

(b) Group of Medium Lobsters + Predator

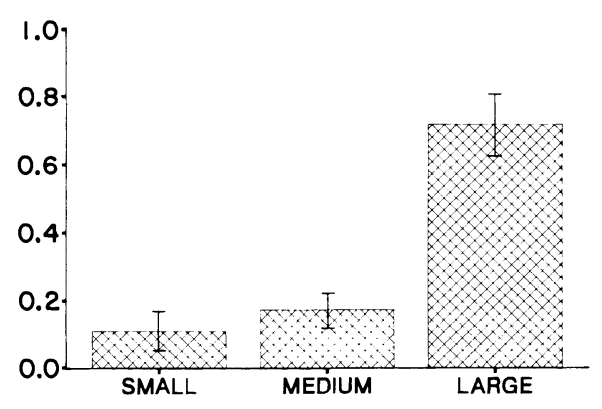

(d) Group of Large Lobsters + Predator

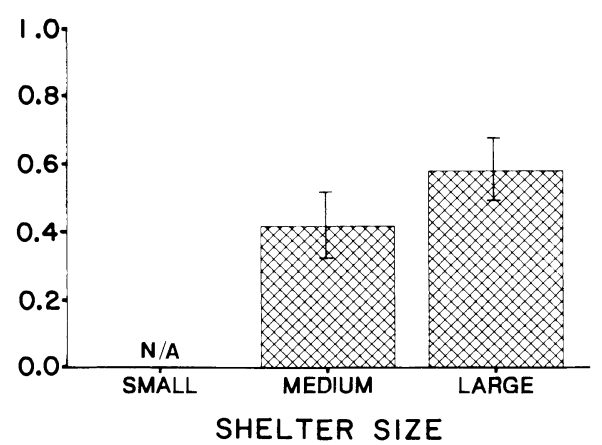

FIG. 8. Den choice in enclosure experiments with a group of medium vs. large lobsters, comparing proportional occupancy in three casita (artificial lobster shelter) sizes as a function of size within a group of lobsters (medium vs. large) and presence or absence of a predator. Values are means $\pm 1 \mathrm{SE}$. N/A indicates that a lobster size class was physically unable to enter that particular casita size.

quency was equivalent between sites (five sampling dates $\times 18$ casitas per site). At the inner-bay site the total abundance in 18 casitas (i.e., 6 small +6 medium +6 large casitas) ranged from a low of 23 lobsters in January 1989, to a high of 99 lobsters in June 1990 (Table 3). This same temporal trend in abundance was evident at the outer-bay site, with total abundance ranging from a low of 7 lobsters in January 1989, to a high of 29 lobsters in June 1990 (Table 3).

Lobster abundance in the casitas varied significantly as a function of site, casita size, and time (Table 4a); however, the site $\times$ casita size and time $\times$ casita size interaction effects were significant (Table 4a), again precluding direct conclusions about the main effects (Underwood 1981). The site $\times$ casita size interaction effect was due to the significantly higher lobster abundance in large casitas at the inner-bay site than at the outer-bay site, and the significantly higher abundance in large over small and medium casitas at the innerbay site (Table $4 b$ ). The time $\times$ casita size interaction effect was due to the significantly higher lobster abundance in large vs. small and medium casitas during April-October 1989 and June 1990, and significantly higher abundance in medium and large casitas vs. small casitas in January 1989 (Table 4b).
Lobster to shelter size relationships. - The mean size and size ranges of spiny lobsters increased with casita size at both sites (Table 3), with large casitas attracting the broadest size range of lobsters at both sites. Medium casitas at both sites attracted and concentrated both medium (46-55 $\mathrm{mm} \mathrm{CL}$ ) and small (35-45 $\mathrm{mm}$ CL) spiny lobsters, whereas small casitas were relatively ineffective at concentrating lobsters (Table 3 ).

Mean lobster size in casitas varied significantly as a function of casita size and sampling date (Table 5a), but not site (Table 5a). However, the site by casita size interaction effect was significant (Table 5a). The interaction effect was due to differences in mean lobster size in large casitas between sites (Table 5b). Lobsters in large casitas were significantly larger at the outer-bay site than inner-bay site (Table 5b). Lobsters were also significantly larger in large casitas compared to small and medium casitas, regardless of site (Table 5b). Overall mean sizes $( \pm 1 \mathrm{SD})$ in large, medium, and small casitas were $68.1 \pm 11.9,43.7 \pm 7.6$, and $39.6 \pm 13.4$ $\mathrm{mm} \mathrm{CL}$, respectively. Lobsters at both sites were significantly larger in June 1990 than January 1989 (Table $5 b)$.

Gregariousness. - The frequency of gregariousness in casitas at the inner-bay site ( 8 out of 10 cases) was 
TABLE 3. Seasonal abundance and sizes (carapace length, CL) of spiny lobsters residing under small, medium, and large casitas (artificial lobster shelters) at two sites (inner bay: sand-seagrass flat, and outer bay: seagrass bed adjacent to coral reefs) during winter (January 1989), spring (April 1989), summer (July 1989 and June 1990), and fall (October 1989).

\begin{tabular}{|c|c|c|c|c|}
\hline \multirow[b]{2}{*}{ Experimental condition } & \multirow[b]{2}{*}{ Total abundance } & \multicolumn{3}{|c|}{ Size $(\mathrm{mm} \mathrm{CL})$} \\
\hline & & Mean \pm SD & Min. & Max. \\
\hline \multicolumn{5}{|c|}{ January 1989} \\
\hline Large casita, inner bay & 14 & $50.2 \pm 14.7$ & 30.0 & 70.9 \\
\hline Large casita, outer bay & 2 & $80.5 \pm 9.5$ & 71.0 & 90.0 \\
\hline Medium casita, inner bay & 8 & $32.5 \pm 9.7$ & 15.0 & 60.1 \\
\hline Medium casita, outer bay & 5 & $38.0 \pm 4.0$ & 30.0 & 40.0 \\
\hline Small casita, inner bay & 1 & $30.0 \quad \cdots$ & $\ldots$ & $\cdots$ \\
\hline Small casita, outer bay & 0 & $\ldots \quad \ldots$ & $\cdots$ & $\cdots$ \\
\hline \multicolumn{5}{|c|}{ April 1989} \\
\hline Large casita, inner bay* & 62 & $60.8 \pm 13.6$ & 35.6 & 81.5 \\
\hline Large casita, outer bay & 11 & $65.3 \pm 17.7$ & 40.0 & 94.3 \\
\hline Medium casita, inner bay* & 12 & $53.7 \pm 9.7$ & 41.0 & 71.0 \\
\hline Medium casita, outer bay & 4 & $42.3 \pm 16.7$ & 30.0 & 71.0 \\
\hline Small casita, inner bay & 1 & $67.5 \quad \ldots$ & $\ldots$ & $\cdots$ \\
\hline Small casita, outer bay & 3 & $31.7 \pm 2.4$ & 30.0 & 35.0 \\
\hline \multicolumn{5}{|c|}{ July 1989} \\
\hline Large casita, inner bay & 82 & $67.6 \pm 16.8$ & 35.0 & 108.1 \\
\hline Large casita, outer bay & 8 & $80.6 \pm 16.9$ & 60.0 & 120.0 \\
\hline Medium casita, inner bay & 2 & $57.5 \pm 2.5$ & 55.0 & 60.0 \\
\hline Medium casita, outer bay & 3 & $40.3 \pm 6.1$ & 33.0 & 48.0 \\
\hline Small casita, inner bay & 4 & $43.8 \pm 2.2$ & 40.0 & 45.0 \\
\hline Small casita, outer bay & 1 & $35.0 \quad \cdots$ & $\ldots$ & $\cdots$ \\
\hline \multicolumn{5}{|c|}{ October 1989} \\
\hline Large casita, inner bay & 56 & $48.5 \pm 14.6$ & 15.2 & 75.6 \\
\hline Large casita, outer bay & 8 & $80.8 \pm 6.6$ & 71.0 & 90.0 \\
\hline Medium casita, inner bay & 2 & $37.5 \pm 7.5$ & 30.0 & 45.0 \\
\hline Medium casita, outer bay & 3 & $38.3 \pm 2.4$ & 35.0 & 40.0 \\
\hline Small casita, inner bay & 2 & $29.3 \pm 1.1$ & 28.2 & 30.3 \\
\hline Small casita, outer bay & 0 & $\cdots \quad \cdots$ & & $\cdots$ \\
\hline \multicolumn{5}{|c|}{ June 1990} \\
\hline Large casita, inner bay & 96 & $65.3 \pm 17.1$ & 29.8 & 105.6 \\
\hline Large casita, outer bay & 22 & $81.3 \pm 15.6$ & 63.2 & 126.7 \\
\hline Medium casita, inner bay & 3 & $49.1 \pm 3.7$ & 45.0 & 53.1 \\
\hline Medium casita, outer bay & 7 & $47.9 \pm 2.4$ & 41.1 & 55.0 \\
\hline Small casita, inner bay & 0 & $\ldots \quad \ldots$ & $\ldots$ & $\cdots$ \\
\hline Small casita, outer bay & 0 & $\cdots$ & $\cdots$ & $\cdots$ \\
\hline
\end{tabular}

* Within one particular triangular station at the inner-bay site, a Nassau grouper (Epinephelus striatus; measuring $\approx 50 \mathrm{~cm}$ fork length) was observed under the large casita, which contained 3 lobsters, whereas 12 lobsters were residing under the medium casita. Nassau grouper readily feed on juvenile spiny lobster (D. B. Eggleston, personal observation).

much greater than at the outer-bay site ( 4 out of 10 cases) in both medium and large casitas (Table 6). Spiny lobsters were also much more gregarious in large casitas ( 8 out of 10 cases) than medium casitas ( 4 out of 10 cases) at both sites (Table 6).

Den choices by small, medium, and large lobsters. Field den choice patterns by small lobsters differed significantly as a function of site but not casita size (Table 7a); however, the site $\times$ casita size interaction effect was significant (Table 7a). Time and all interaction effects associated with time were not significant (Table 7a). The site $\times$ casita size interaction effect was due to differences in the degree to which small lobsters inhabited different-sized casitas between sites. At the inner-bay site, small lobsters occupied large casitas significantly more often than small and medium casitas
(Table 7b, Fig. 9). Conversely, at the outer-bay site, small lobsters occurred significantly more often in medium casitas than small and large casitas (Table $7 \mathrm{~b}$, Fig. 9), though the absolute difference was small compared to abundances at the inner-bay site. In addition, small lobsters were more abundant in large casitas at the inner-bay than outer-bay site (Table 7b, Fig. 9).

Den choice patterns by medium lobsters also varied significantly between sites but not according to casita size (Table 8a); similarly, the site $\times$ casita size interaction effect was significant (Table $8 \mathrm{a}$ ). Time and all interaction effects associated with time were also not significant (Table $8 \mathrm{a}$ ). The site $\times$ casita size interaction effect was due to significantly higher numbers of medium lobsters residing under large casitas at the innerbay site compared to the outer-bay site, and to the 
TABLE 4. Effects of site (inner bay: sand-seagrass flat and outer bay: seagrass bed adjacent to coral reefs), casita size (small, medium, and large), and time (January 1989, April 1989, July 1989, October 1989, and June 1990) upon log-transformed numbers of lobsters occupying casitas (artificial lobster shelters).

(a) Three-way repeated-measures ANOVA table (model I).

\begin{tabular}{lcccc}
\multicolumn{1}{c}{ Source of variation } & ss & df & MS \\
\hline & Tests of hypotheses for between-subject effects & & \\
Site & 6.30 & 1 & 6.30 & $9.33 \dagger$ \\
Casita size & 49.35 & 2 & 24.67 & $36.53^{* * *}$ \\
Site $\times$ Casita size & 14.12 & 2 & 7.06 & $10.45^{* * *}$ \\
Error & 20.26 & 30 & 0.68 & $2.82^{*}$ \\
& Tests of hypotheses for within-subject effects & & 0.86 \\
Time & 3.44 & 4 & 0.16 & NS \\
Time $\times$ site & 0.65 & 4 & 1.14 & $3.74^{* * *}$ \\
Time $\times$ Casita size & 9.10 & 8 & 0.20 & $0.64 \mathrm{NS}$ \\
Time $\times$ Site $\times$ Casita size & 1.57 & 120 & 0.30 &
\end{tabular}

(b) Ryan's $Q$ tests of log-transformed numbers of lobsters for the site $\times$ casita size and time $\times$ casita size interaction effects. Treatment levels that are not significantly different at the .05 level share an underline. Treatment levels are arranged in increasing order of abundance.

Interaction

\begin{tabular}{|c|c|c|c|c|c|}
\hline \multicolumn{2}{|l|}{ Site } & \multicolumn{4}{|c|}{ Casita size } \\
\hline \multicolumn{2}{|l|}{ Inner bay } & $\underline{\text { Small }}$ & & & $\underline{\text { Large }}$ \\
\hline \multicolumn{2}{|l|}{ Outer bay } & Small & & & Medium \\
\hline \multicolumn{2}{|c|}{ Casita size } & \multicolumn{4}{|c|}{ Site } \\
\hline \multicolumn{2}{|l|}{ Small } & \multicolumn{2}{|c|}{ Inner bay } & \multicolumn{2}{|c|}{ Outer bay } \\
\hline Medium & & \multicolumn{2}{|c|}{ Inner bay } & \multicolumn{2}{|c|}{ Outer bay } \\
\hline Large & & \multicolumn{2}{|c|}{ Outer bay } & \multicolumn{2}{|c|}{ Inner bay } \\
\hline \multicolumn{2}{|c|}{ Time } & \multicolumn{4}{|c|}{ Casita size } \\
\hline \multicolumn{2}{|c|}{ January 1989} & $\underline{\text { Small }}$ & & & Large \\
\hline \multicolumn{2}{|c|}{ April 1989} & Small & & & $\underline{\text { Large }}$ \\
\hline \multicolumn{2}{|c|}{ July 1989} & Medium & & & Large \\
\hline \multicolumn{2}{|c|}{ October 1989} & Small & & & Large \\
\hline \multicolumn{2}{|c|}{ June 1990} & Small & & & Large \\
\hline \multicolumn{2}{|c|}{ Casita size } & \multicolumn{4}{|c|}{ Time } \\
\hline \multirow{3}{*}{$\begin{array}{l}\text { Small } \\
\text { Medium } \\
\text { Large }\end{array}$} & Oct. 1989 & Jan. 1989 & June 1990 & April 1989 & July 1989 \\
\hline & July 1989 & Oct. 1989 & Jan. 1989 & June 1990 & April 1989 \\
\hline & Jan. 1989 & Oct. 1989 & July 1989 & April 1989 & June 1990 \\
\hline
\end{tabular}

${ }^{*} P<.05, \dagger P<.005,{ }^{* * *} P<.001$, NS $P>.05$.

significantly higher abundances in large than medium casitas at the inner-bay site (Table 8b, Fig. 10), similar to the trend observed for small lobsters (compare Figs. 9 and 10).

Den residency by large lobsters in large casitas differed significantly by site and time (Table 9a); the site $\times$ time interaction effect was not significant (Table $9 a$ ). There were significantly more large lobsters in large casitas at the inner-bay site than at the outer-bay site, irrespective of sampling date (Fig. 11). Moreover, large lobsters were least abundant during January 1989 compared to later dates at both sites (Table 9b, Fig. 11).

\section{DisCUSSION}

Predation risk, social condition, and the scaling of lobster size to shelter size jointly regulated den choice patterns of adult and juvenile Panulirus argus in our field experiments and observations. Through the use of artificial lobster shelters (casitas) scaled according to lobster size, we were able to standardize den size and availability in natural habitats that differed primarily in the potential for gregarious interactions, and thereby assess the relative importance of sociality in determining shelter choice. Enclosure experiments allowed us to examine the interactive effects of social condition, shelter size, and predation risk upon den choices. The experimental and observational field results were strikingly similar - when conspecific density and predation risk were low, lobsters resided primarily in shelters whose dimensions were scaled to their own; when conspecific density was high and predation risk was low, lobsters resided predominantly in large shel- 
TABLE 5. Effects of site (inner bay: sand-seagrass flat, and outer bay: seagrass bed adjacent to coral reefs), casita size (small, medium, and large) and sampling date (January 1989, April 1989, July 1989, October 1989, and June 1990) upon the mean size (carapace length) of lobsters occupying casitas (artificial lobster shelters).

(a) Three-way ANOVA table (model I).

\begin{tabular}{lrrrr}
\multicolumn{1}{c}{ Source of variation } & \multicolumn{1}{c}{ ss } & df & MS & \multicolumn{1}{c}{$F$} \\
\hline Site & 541.36 & 1 & 541.36 & 6.09 NS† \\
Casita size & 13910.00 & 2 & 6955.00 & $78.23^{* * * * \neq}$ \\
Sampling date & 1571.11 & 4 & 392.78 & $4.42 \S$ \\
Site $\times$ Casita size & 2366.44 & 2 & 1183.22 & $13.31^{* * * *}$ \\
Site $\times$ Date & 1043.21 & 4 & 260.80 & $2.93 \mathrm{NS}$ \\
Casita size $\times$ Date & 972.30 & 7 & 138.90 & $1.56 \mathrm{NS}$ \\
Site $\times$ Casita size $\times$ Date & 308.82 & 5 & 61.76 & $0.70 \mathrm{NS}$ \\
Error & 4800.66 & 54 & 88.90 &
\end{tabular}

(b) Ryan's $Q$ tests of mean lobster sizes per casita for the sampling date main effect and the Site $\times$ Casita size interaction effect. Treatment levels that are not significantly different at the .05 level share an underline. Treatment levels are arranged in increasing order of lobster size.

Main effect

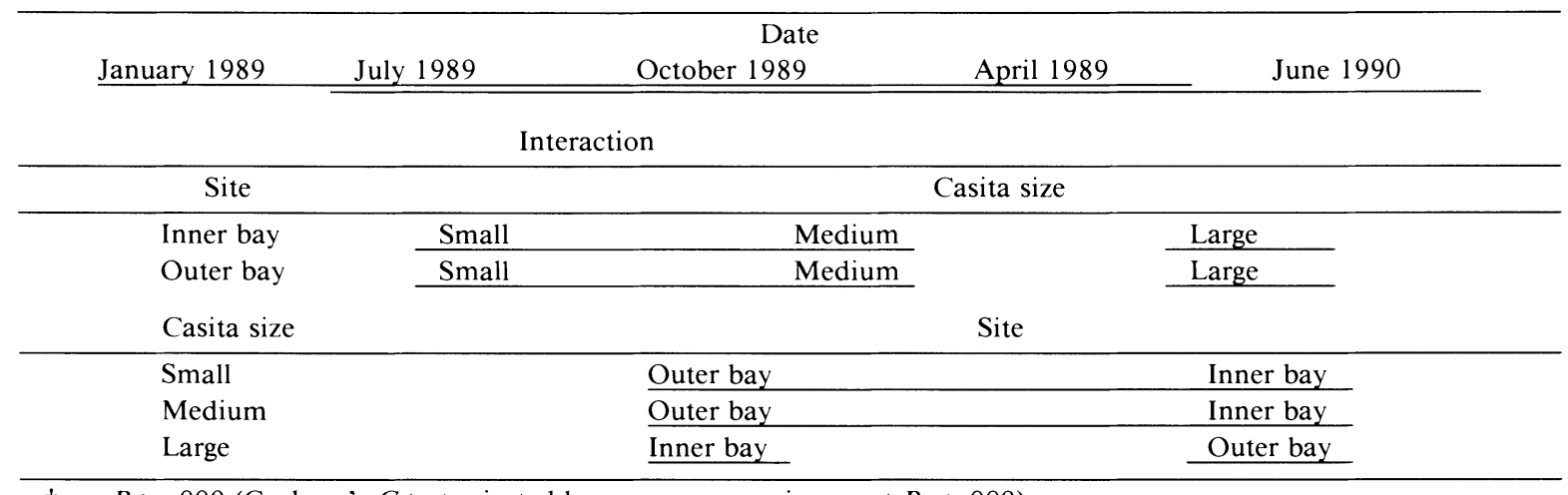

$\dagger$ NS: $P>.009$ (Cochran's $C$ test rejected homogeneous variances at $P<.009$ ).

$\ddagger * * * * P<.0001$.

$\S P<.005$.

TABLE 6. Lobster abundance and occupancy rates in medium and large casitas (artificial lobster shelters) at the two sites (inner bay vs. outer bay) over time (January, April, July, and October 1989, and June 1990) compared with the expected frequencies generated by a two-tailed Poisson distribution.

\begin{tabular}{|c|c|c|c|c|}
\hline Site & Casita size & Date & $\begin{array}{l}\text { Mean no. } \\
\text { lobsters per } \\
\text { casita }\end{array}$ & No. lobsters within each of 6 casitas \\
\hline \multirow{10}{*}{ Inner bay } & Large & January 1989 & 2.33 & $0,0,1,2,5,6^{*}$ \\
\hline & & April 1989 & 10.33 & $3^{*}, 6,7,8,8,30 \dagger$ \\
\hline & & July 1989 & 13.67 & $0^{* * *}, 10,10,14,23^{*}, 25 \dagger$ \\
\hline & & October 1989 & 9.33 & $0^{* * *}, 3^{*}, 3 *, 7,12,31 \dagger$ \\
\hline & & June 1990 & 16.00 & $1^{* * *}, 2^{* * *}, 13,15,25^{*}, 40 \dagger$ \\
\hline & Medium & January 1989 & 1.33 & $0,0,0,1,3,4^{*}$ \\
\hline & & April 1989 & 1.83 & $0,0,0,0,0,11 \dagger$ \\
\hline & & July 1989 & 0.33 & $0,0,0,0,1,1 ;$ all Ns \\
\hline & & October 1989 & 0.33 & $0,0,0,0,1,1 ;$ all NS \\
\hline & & June 1990 & 0.50 & $0,0,0,0,1,2^{*}$ \\
\hline \multirow[t]{10}{*}{ Outer bay } & Large & January 1989 & 0.33 & $0,0,0,0,1,1 ;$ all Ns \\
\hline & & April 1989 & 1.83 & $0,1,1,2,3,4 ;$ all Ns \\
\hline & & July 1989 & 1.33 & $0,0,1,1,2,4^{*}$ \\
\hline & & October 1989 & 1.33 & $0,0,0,2,2,4^{*}$ \\
\hline & & June 1990 & 3.67 & $1,1,2,3,7,8^{*}$ \\
\hline & Medium & January 1989 & 0.83 & $0,0,1,1,1,2 ;$ all Ns \\
\hline & & April 1989 & 0.67 & $0,0,0,1,1,2 ;$ all Ns \\
\hline & & July 1989 & 0.50 & $0,0,0,1,1,1 ;$ all Ns \\
\hline & & October 1989 & 0.50 & $0,0,0,0,1,2^{*}$ \\
\hline & & June 1990 & 1.67 & $0,0,1,2,2,2 ;$ all NS \\
\hline
\end{tabular}


TABLE 7. Effects of site (inner bay: sand-seagrass flat, and outer bay: seagrass bed adjacent to coral reefs), casita size (small, medium, and large) and time (January 1989, April 1989, July 1989, October 1989, and June 1990) upon logtransformed numbers of small lobsters occupying casitas (artificial lobster shelters).

(a) Three-way repeated-measures ANOVA table (model I).

\begin{tabular}{lrrrr} 
Source of variation & \multicolumn{1}{c}{ ss } & df & MS & $F$ \\
\hline \multicolumn{4}{c}{ Tests of hypotheses for between-subject effects } \\
Site & 2.48 & 1 & 2.48 & $4.71^{*}$ \\
Casita size & 3.28 & 2 & 1.64 & $3.11 \mathrm{NS}$ \\
Site $\times$ Casita size & 6.60 & 2 & 3.31 & $6.26 \dagger$ \\
Error & 15.80 & 30 & 0.53 & \\
\multicolumn{5}{c}{ Tests of hypotheses for within-subject effects } \\
Time & 0.23 & 4 & 0.06 & $0.32 \mathrm{NS}$ \\
Time $\times$ Site & 0.31 & 4 & 0.08 & $0.43 \mathrm{NS}$ \\
Time $\times$ Casita size & 2.03 & 8 & 2.54 & $1.42 \mathrm{NS}$ \\
Time $\times$ Site $\times$ & \multicolumn{4}{c}{} \\
$\quad$ Casita size & 1.03 & 8 & 0.13 & $0.72 \mathrm{NS}$ \\
Error (Time) & 21.43 & 120 & 0.18 &
\end{tabular}

(b) Ryan's $Q$ tests of log-transformed numbers of small lobsters for the Site $\times$ Casita size interaction effect. Treatment levels that are not significantly different at the .05 level share an underline. Treatment levels are arranged in increasing order of abundance.

Interaction

\begin{tabular}{|c|c|c|c|}
\hline Site & & Casita siz & \\
\hline Inner bay & $\underline{\text { Small }}$ & Medium & $\underline{\text { Large }}$ \\
\hline Outer bay & Large & Small & Medium \\
\hline Casita size & \multicolumn{3}{|c|}{ Site } \\
\hline Small & Inner bay & & Outer bay \\
\hline Medium & Inner bay & & Outer bay \\
\hline Large & Outer bay & & Inner bay \\
\hline
\end{tabular}

${ }^{*} P<.05, \dagger P<.005$, NS $P>.05$.

ters offering the highest potential for gregariousness; when conspecific density and predation risk were high, lobsters shifted to gregarious habitation in smaller, scaled shelters; and, when predation risk was high and conspecific density was low, lobsters occupied smaller shelters.

\section{Interactive effects of shelter and lobster size, predation risk, and social condition upon den choice dynamics}

Den choice patterns in the enclosure experiments partially corresponded to those expected as a result of lobster- and shelter-size-specific survival patterns in the field. Previous field tethering experiments indicated that survival of small and medium lobsters was generally dependent on casita size, with small and medium casitas affording the best protection to small and medium lobsters, respectively (Eggleston et al. 1990). In the absence of predation risk, medium and large solitary lobsters displayed similar den choice patterns by choosing large, then medium, shelters, whereas small solitary lobsters chose small and then medium shelters (Fig. 5). When a predator was added to either the sol- itary small or medium lobster treatment, the two size classes responded similarly; den choices shifted from small or large casitas to $100 \%$ occupancy in medium casitas (compare Figs. 6b and $7 \mathrm{~b}$ ). Thus, under high predation risk, medium lobsters chose casitas that offered the highest degree of physical refuge, whereas small lobsters did not. The latter result was counterintuitive in that we expected small lobsters under high predation risk to select the safer, small casitas rather than riskier, medium casitas. However, medium casitas simultaneously offer the opportunity for gregariousness with larger conspecifics and exclude larger predators.

Grouped lobsters demonstrated similar den choice patterns as solitary lobsters under variable predation risk. Lobsters were gregarious in larger shelters under low predation risk, whereas lobsters were generally gregarious within smaller, safer shelters under high predation risk. For instance, groups of medium and large lobsters under reduced predation risk were gregarious

(a)
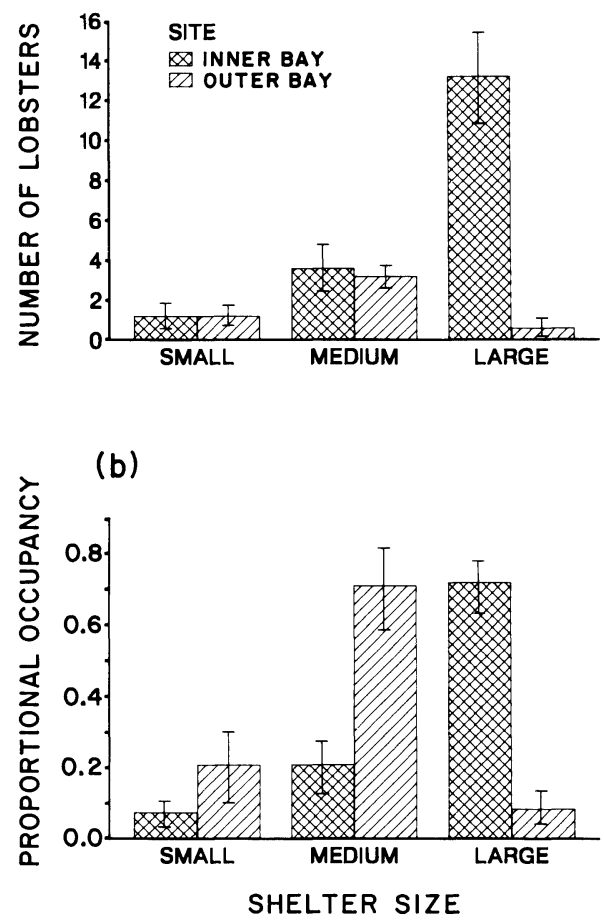

FIG. 9. Results of field experiments examining (a) total numbers and (b) proportional occupancy of small (35-45 mm carapace length) spiny lobsters in three casita (artificial lobster shelter) sizes between two sites (inner bay: sand-seagrass flat, and outer bay: seagrass bed adjacent to coral reefs). Proportional occupancy is illustrated to clearly define site-specific den habitation patterns. Proportions were calculated as the total number of small lobsters inhabiting 6 casitas of each particular size (small, medium, or large) divided by the total number of small lobsters inhabiting all 18 casitas at each site. Data are means $\pm 1 \mathrm{SE}$. 
TABLE 8. Effects of site (inner bay: sand-seagrass flat, and outer bay: seagrass bed adjacent to coral reefs), casita size (medium and large) and time (January 1989, April 1989, July 1989 , October 1989 , and June 1990) upon log-transformed numbers of medium lobsters occupying casitas (artificial lobster shelters). $\dagger$

(a) Three-way repeated-measures ANOVA table (model I).

\begin{tabular}{lcccc} 
Source of variation & ss & df & MS & $F$ \\
\hline \multicolumn{4}{c}{ Tests of hypotheses for between-subject effects } \\
Site & 2.29 & 1 & 2.29 & $4.72^{*}$ \\
Casita size & 1.31 & 1 & 1.31 & $2.71 \mathrm{NS}$ \\
Site $\times$ Casita size & 3.05 & 1 & 3.05 & $6.30^{*}$ \\
Error & 9.74 & 20 & 0.49 & \\
\multicolumn{5}{c}{ Tests of hypotheses for within-subject effects } \\
Time & 1.24 & 4 & 0.31 & $1.53 \mathrm{NS}$ \\
Time $\times$ Site & 0.21 & 4 & 0.05 & $0.27 \mathrm{NS}$ \\
Time $\times$ Casita size & 0.24 & 4 & 0.06 & $0.28 \mathrm{NS}$ \\
Time $\times$ Site $\times$ & & & & \\
$\quad$ Casita size & 0.59 & 4 & 0.15 & $0.75 \mathrm{NS}$ \\
Error (Time) & 15.97 & 80 & 0.20 &
\end{tabular}

(b) Ryan's $Q$ tests of log-transformed numbers of medium lobsters for the Site $\times$ Casita size interaction effect. Treatment levels that are not significantly different at the .05 level share an underline. Treatment levels are arranged in increasing order of abundance.

\begin{tabular}{lll}
\multicolumn{2}{c}{ Interaction } \\
\hline \multicolumn{1}{c}{ Site } & \multicolumn{2}{c}{ Casita size } \\
\hline $\begin{array}{l}\text { Inner bay } \\
\text { Outer bay }\end{array}$ & $\frac{\text { Medium }}{\text { Medium }}$ & $\frac{\text { Large }}{\text { Large }}$ \\
\cline { 2 - 3 } Casita size & \multicolumn{2}{c}{ Site } \\
\hline $\begin{array}{l}\text { Medium } \\
\text { Large }\end{array}$ & Outer bay & Inner bay \\
\hline
\end{tabular}

$* P<.05$, NS $P>.05$.

$\dagger$ The small casita size was eliminated from the analysis because no medium lobsters were observed in small casitas.

within large and sometimes medium casitas (compare Figs. $8 \mathrm{a}$ and $8 \mathrm{c}$ ). Under high predation risk, however, there was a tendency for groups of medium and large lobsters to shift den choices to smaller shelters (Fig. 8). Similarly, the majority of small lobsters grouped with medium conspecifics, and medium lobsters grouped with large conspecifics also shifted to smaller shelters in the presence of a predator (compare Figs. $6 \mathrm{c}$ and $6 \mathrm{~d}$ with Figs. $8 \mathrm{a}$ and $8 \mathrm{~b}$, and Figs. $7 \mathrm{c}$ and $7 \mathrm{~d}$ with Figs. $8 \mathrm{c}$ and $8 \mathrm{~d}$ ). Although $56 \%$ of small lobsters grouped with large conspecifics under high predation risk were gregarious within medium casitas or occupied the small casitas, $44 \%$ occupied the large casitas with $64 \%$ of the large lobsters (compare Figs. 6f and 8d). These results suggest that for small juvenile lobsters the presence or absence of conspecifics was just as important as shelter size in determining den choice, whereas shelter size was more important than presence of conspecifics in regulating den choices of medium lobsters. If shelter is limiting for small juvenile lobsters, behavior that places small lobsters in large shelters with conspecifics would enhance survival compared to behavior where- by lobsters search for limited but appropriately scaled shelter. Conversely, medium juvenile lobsters may demonstrate low survival in large shelters with larger conspecifics if piscine predators selectively prey on these lobsters.

$$
\begin{gathered}
\text { Habitat-specific and size-specific } \\
\text { patterns of shelter use }
\end{gathered}
$$

The field observations from this study are consistent with the hypothesis that the abundance of conspecifics can be a limiting resource in certain habitats, if low lobster abundance reduces the potential for gregarious interactions, and thereby limits the protective capacity of specific shelters. The field observations illustrate that shelter-seeking behavior of Panulirus argus is highly flexible to habitat conditions and shelter features. For

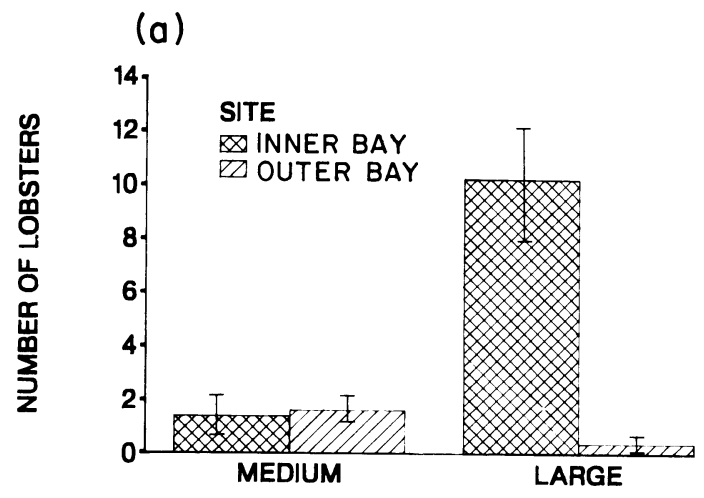

\section{(b)}

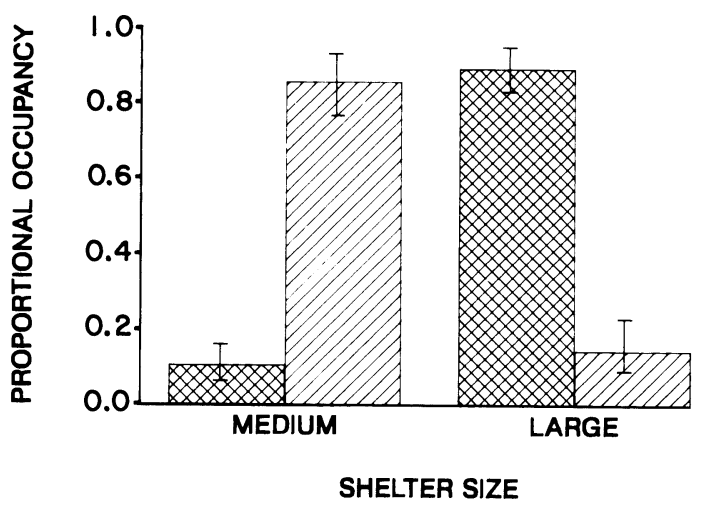

FIG. 10. Results of field experiments examining (a) total numbers and (b) proportional occupancy of medium (46-55 $\mathrm{mm}$ carapace length) spiny lobsters in two casita (artificial lobster shelter) sizes between two sites (inner bay: sand-seagrass flat, and outer bay: seagrass bed adjacent to coral reefs). As above, proportional occupancy is illustrated to clearly define site-specific den habitation patterns. Proportions were calculated as the total number of medium lobsters inhabiting 6 casitas of a particular size (small, medium, or large) divided by the total number of medium lobsters inhabiting all 18 casitas at each site. Values are means $\pm 1 \mathrm{SE}$. 
TABLE 9. Effects of site (inner bay: sand-seagrass flat, and outer bay: seagrass bed adjacent to coral reefs), and time (January 1989, April 1989, July 1989, October 1989, and June 1990) upon log-transformed numbers of large lobsters occupying large casitas (artificial lobster shelters). $\ddagger$

(a) Two-way repeated-measures ANOVA table (model 1 ).

Source of variation

ss $\quad$ df

MS

$F$

Tests of hypotheses for between-subject effects

$\begin{array}{lrrrr}\text { Site } & 6.68 & 1 & 6.68 & 5.11^{*} \\ \text { Error } & 13.07 & 10 & 1.31 & \\ & \text { Tests of hypotheses for within-subject effects } & & 4.06 \dagger \\ \text { Time } & 5.34 & 4 & 1.33 & 1.34 \\ \text { Time } \times \text { Site } & 1.77 & 4 & 0.44 & 0.23\end{array}$

(b) Ryan's $Q$ tests of mean number of large lobsters (log-transformed) occupying large casitas for the sampling date main effect. Treatment levels that are not significantly different at the .05 level share an underline. Treatment levels are arranged in increasing order of abundance.

\begin{tabular}{cccccc} 
& Main effect \\
\hline January 1989 & Date & July 1989 & June 1990 \\
\hline
\end{tabular}

$* P<.05, \dagger P<.005$.

$\ddagger$ The small casita size was eliminated from the analysis because large lobsters could not enter small shelters. The medium casita size was eliminated from the analysis because only 2 out of 126 large lobsters were observed under a medium casita during the study.

example, when conspecific density was relatively high (inner-bay site), small and medium lobsters occupied large casitas with large conspecifics (Figs. 9 and 10). In contrast, when conspecific density was relatively low (outer-bay site), small and medium lobsters generally chose medium casitas, similar to the den choice patterns observed in the enclosure experiments for solitary small and medium lobsters in the presence of a predator (compare Figs. 9b with $6 \mathrm{~b}$, and $10 \mathrm{~b}$ with $7 \mathrm{~d}$ ). These results corresponded well with shelter- and habitat-specific patterns of gregariousness in the field. The frequency of gregariousness was much higher at the inner-bay site compared to the outer-bay site, and much higher in large vs. medium casitas at both sites. Small casitas were only occasionally inhabited by small lobsters and never by medium lobsters (compare Figs. 9 and 10). The collective evidence from previous field and laboratory studies suggests that when conspecifics are abundant, gregarious behavior might be more effective in excluding predators from dens (Berrill 1975, Cobb 1981) and in facilitating predator detection and avoidance (Berrill 1975, Zimmer-Faust et al. 1985) than solitary residency in smaller shelters. The flexible shelter-seeking behavior of lobsters observed in our study suggests that survival may be similar whether lobsters are gregarious within large shelters or solitary residents within scaled shelters. However, additional studies are required to determine how survival of juvenile lobsters varies under both conditions.

Given the relative importance of conspecifics and shelter size to the observed dynamics of spiny lobster shelter selection in our study, commercial harvesting of large juvenile and adult lobsters from nursery habitats should be viewed with caution. For example, re- duced conspecific densities in fished areas might cause small juvenile lobsters to search for and occupy a more limited size range of shelters in the absence of the increased protection afforded by gregarious residency. Hence, predation-induced mortality rates of juvenile lobsters may be higher in fished than protected areas. In a somewhat analogous system, the presence of adult red sea urchins (Strongylocentrotus franciscanus) is apparently critical to the recruitment success of this species (Tegner and Dayton 1977). Abundance of juvenile red sea urchins was highest underneath the test or spine canopies of conspecific adults (Tegner and Dayton 1977), especially where substrate afforded little cover, or in the presence of certain predators (Tegner and

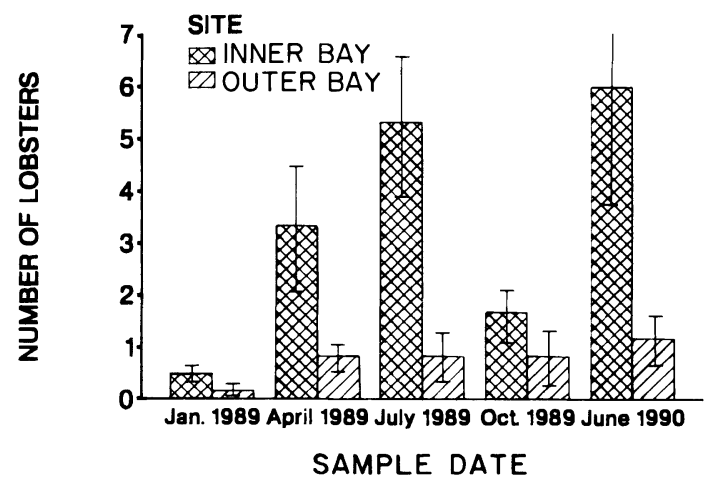

FIG. 11. Results of field experiments examining the total numbers of large (70-80 mm carapace length) spiny lobsters in large casitas (artificial lobster shelters) between two sites (inner bay: sand-seagrass flat, and outer bay: seagrass bed adjacent to coral reefs) on five sampling dates. Values are means $\pm 1 \mathrm{SE}$. 
a) Without predators / low predation risk

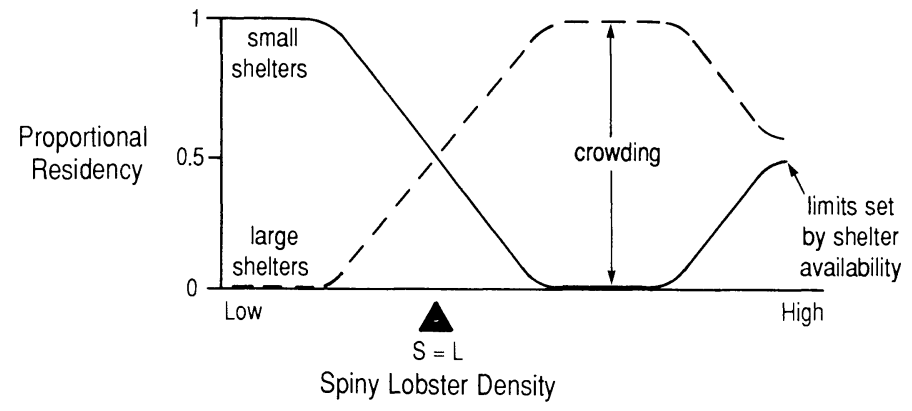

b) With predators / high predation risk

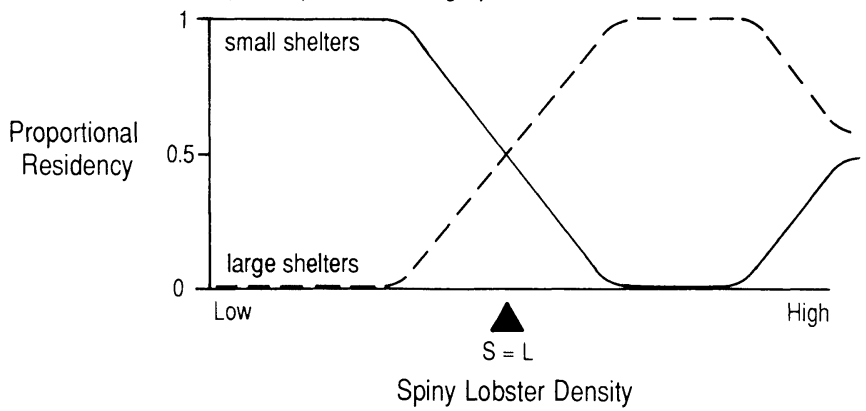

FIG. 12. Model of hypothesized relationship among shelter size, spiny lobster density, and spiny lobster proportional residency in shelters. $\mathrm{S}=$ small shelter and $\mathrm{L}=$ large shelter. Although proportional residency is represented as a threshold (sigmoid) function at low to moderate lobster densities, the relationship between lobster density and proportional residency could also be represented as a linear increase (or decrease in small shelters) to an upper (lower) plateau or as a hyperbolic increase (or decrease in small shelters) to an upper (lower) asymptote.

Dayton 1977, Sloan et al. 1987). When adult sea urchins were experimentally fished (all animals $>95 \mathrm{~mm}$ were removed) from reefs in the Point Loma kelp forest near San Diego, California, settlement and survival of previously settled juveniles was significantly reduced (Tegner and Dayton 1977).

\section{Conceptual framework for examining shelter selection dynamics}

Limitations to the distribution and abundance of spiny lobsters within shelters are a consequence of complex interactions involving lobster density, and the sizes of the lobster, shelter, and predator (Eggleston et al. 1990). For instance, the maximum size of a lobster within a particular shelter is limited by the size of the shelter, whereas the minimum size is limited by shelter-associated predators (Eggleston et al. 1990). Our results suggest that gregarious behavior expands the minimum size limit of lobsters that can survive within large shelters. We have commonly observed groups of large lobsters with their antennae protruding from each opening of a casita, and small juveniles located within the center of the lobster aggregation. These observations are consistent with those predicted by "selfish herding" (sensu Hamilton 1971), whereby individuals position themselves among conspecifics to reduce their own risk of being eaten. However, lobster densities within a shelter may reach a critical threshold whereby intra- and interspecific aggression forces subordinate individuals to find another den (Berrill 1975, Cobb 1981); this process may be further intensified by predators (Sih 1982, Mittlebach 1988). Conversely, there may be a critical lobster-density threshold below which the refuge capacity of shelter scaling outweighs the enhanced vigilance provided by low numbers of conspecifics. Thus, predictions of the distribution and abundance of social, crevice-dwelling species must be based not only on available habitat architecture or shelter scaling, but also on the impact of gregariousness.

Den habitation patterns of Panulirus argus may be modelled schematically (Fig. 12) based on the following features. Under low predation risk (Fig. 12a), residency in large shelters will increase (or decrease in small shelters) in a sigmoid fashion as lobsters become gregarious above some low lobster-density threshold, and reach an asymptote when large shelters reach their maximum carrying capacity. Thereafter, occupancy declines in large shelters (or increases in small shelters) to an intermediate value as limited by the availability of shelter in a given habitat. There is also the possibility that the function between lobster proportional occupancy in small and large shelters and lobster density is linear or hyperbolic rather than sigmoid (Fig. 12). Under high predation risk (Fig. 12b), the lobster den- 
sity above which residency in large shelters increases (or decreases in small shelters) is higher, compared to that under low predation risk, due to the tendency of lobsters to scale themselves with shelter size in the presence of a predator. Thereafter, lobsters demonstrate the same den use patterns exhibited above (see Fig. 12a). This model reflects the dynamic behavioral flexibility (sensu Mangel and Clark 1988) inherent in spiny lobster den selection as a function of varying abundances of predators, conspecifics, and suitably scaled shelters.

\section{Conclusions}

Mobile prey attempt to minimize predatory mortality by modifying their microdistribution and behavior in the presence of predators (Charnov 1976, Werner et al. 1983, Sih 1986, Butler 1988, Bland and Temple 1990). Recent experiments indicate that predators play important direct and indirect roles in the habitat distribution of many mobile organisms by causing prey to aggregate in social or physical refugia, or, in the case of cryptic prey, disperse to minimize predation (Pulliam 1989 and references therein). Results from this study provide a strong empirical example of how predation risk is perceived by mobile, shelter-seeking prey, and the extent to which prey can behaviorally control their risk of predation. Predation risk appears to be the driving force behind the distribution and abundance of spiny lobsters in this study since the relative importance of shelter scaling and gregariousness changed with predation risk.

Spatial and temporal variations in spiny lobster group size also support our contention that conspecifics may be viewed as a limiting resource in certain habitats, since the reduced potential for gregarious interactions at the outer-bay site limited den choice patterns of Panulirus argus. Although ecologists have long recognized that animal group size can (1) be limited by the proximity to critical resources such as food and shelter, (2) be limited by predators, or (3) track environmental periodicities (Pulliam and Caraco 1984), they have seldom considered conspecific density as a potentially limiting resource.

Our results illustrate the importance of considering structural complexity and sociality in determining the distribution and abundance of mobile, shelter-seeking prey, particularly under variable predation risk. Manipulating lobster size, predation risk, and shelter size with standardized lobster dens allowed us to assess the interactive influence of these factors upon shelter selection. Moreover, the use of standardized dens of different sizes allowed us to examine habitat- and lobstersize-specific den habitation patterns in the field. By defining the critical determinants of shelter choice for Panulirus argus, we have provided a conceptual and empirical framework for identifying how variations in the availability of resources, such as conspecifics and appropriately scaled structural refuges, influence the distribution and abundance of social, shelter-dwelling species.

\section{ACKNOWLEDGMENTS}

We are especially grateful to D. Miller for his abundant advice as well as technical and logistical support, and R. Wicklund and G. Wenz of the Caribbean Marine Research Center for their administrative guidance. We thank L. Coba-Cetina, T. Camarena-Luhrs, and E. Sosa-Cordero with the Centro de Investigaciones de Quintana Roo, J. Cohen, J. Eggleston, K. Kennedy, and numerous Earthwatch volunteers for their able field assistance. Special thanks to Armando Lopez and Sonja Lillvick for the fine accommodations and logistical support. We thank M. Butler, S. Cobb, W. Herrnkind, R. Steneck, and an anonymous referee for critical comments. This work was funded by the National Science Foundation (INT-8617945 to D. Miller and R. Lipcius and OCE 87-00414 to R. Lipcius and A. Hines), Sigma-Xi, Earthwatch-The Center for Field Research, the National Undersea Research Program of the National Oceanic and Atmospheric Administration, the Caribbean Marine Research Center, the Commonwealth of Virginia, and a generous donation from Lewis L. Glucksman. This paper is also Contribution Number 1681 from the Virginia Institute of Marine Science.

\section{Literature Cited}

Altmann, S. A. 1974. Baboons, space, time and energy. American Zoologist 14:221-248

Berrill, M. 1975. Gregarious behavior of juveniles of the spiny lobster, Panulirus argus (Crustacea: Decapoda). Bulletin of Marine Science 25:515-522.

Bland, J. D., and S. A. Temple. 1990. Effects of predationrisk on habitat use by Himalayan Snowcocks. Oecologia (Berlin) 82:187-191.

Butler, M. J., IV. 1988. In situ observations of bluegill (Lepomis macrochirus Raf.) foraging behavior: the effects of habitat complexity, group size, and predators. Copeia 1988: 939-944.

Caddy, J. F. 1986. Modelling stock-recruitment processes in Crustacea: some practical and theoretical perspectives. Canadian Journal of Fisheries and Aquatic Sciences 43: 2330-2344.

Charnov, E. L. 1976. Optimal foraging: attack strategy of a mantid. American Naturalist 110:141-151.

Cobb, J. S. 1981. Behaviour of the Western Australian spiny lobster, Panulirus cygnus George, in the field and laboratory. Australian Journal of Marine and Freshwater Research 31:399-409.

Coull, B. C., and J. B. J. Wells. 1983. Refuges from fish predation: experiments with phytal meiofauna from the New Zealand rocky intertidal. Ecology 64:1599-1609.

Crowder, L. B., and W. E. Cooper. 1982. Habitat structural complexity and the interaction between bluegills and their prey. Ecology 63:1802-1813.

Cruz, R., and R. Brito. 1986. Ecologia de la langosta (Panulirus argus) al SE de Isla de la Juventud. I. Colonizacion de arrecifes artificiales. Revista de Investigaciones Marinas 7:3-17.

Curio, E. B. 1978. The adaptive significance of avian mobbing. Zeitschrift für Tierpsychologie 48:175-183.

Day, R. W., and G. P. Quinn. 1989. Comparisons of treatments after an analysis of variance in ecology. Ecological Monographs 59:433-463.

Dominey, W. J. 1983. Mobbing in colonially nesting fishes, especially the bluegill, Lepomis macrochirus. Copeia 1983: 1086-1088.

Eggleston, D. B., R. N. Lipcius and D. L. Miller. In press a. Artificial shelters and the survival of juvenile Caribbean spiny lobster: spatial, habitat and lobster size effects. United States National Marine Fisheries Service Fishery Bulletin. 
Eggleston, D. B., R. N. Lipcius, and D. L. Miller. In press $b$. Enhancement of spiny lobster survival by artificial shelters: habitat, scaling, and spatial effects upon predation intensity. Gulf and Caribbean Fisheries Institute $\mathbf{4 2}$.

Eggleston, D. B., R. N. Lipcius, D. L. Miller, and L. CobaCetina. 1990. Shelter scaling regulates survival of juvenile Caribbean spiny lobster Panulirus argus. Marine Ecology Progress Series 62:70-88.

Einot, I., and K. R. Gabriel. 1975. A study of the powers of several methods of multiple comparisons. Journal of the American Statistical Association 70:574-583.

Emlen, S. T., and L. W. Oring. 1977. Ecology, sexual selection, and the evolution of mating systems. Science 197: 215-223.

Ford, R. F., B. F. Phillips, and L. M. Joll. 1988. Experimental manipulation of population density and its effects on growth and mortality of juvenile western rock lobsters, Panulirus cygnus George. United States National Marine Fisheries Service Fishery Bulletin 86:773-787.

Gotceitas, V., and P. Colgan. 1989. Predator foraging success and habitat complexity: quantitative test of the threshold hypothesis. Oecologia (Berlin) 80:158-166.

Hacker, S. D., and R. S. Steneck. 1990. Habitat architecture and the abundance and body-size-dependent habitat selection of a phytal amphipod. Ecology 71:2269-2285.

Hamilton, W. D. 1971. Geometry for the selfish herd. Journal of Theoretical Biology 31:295-311.

Heck, K. L., Jr., and L. B. Crowder. 1991. Habitat structure and predator-prey interactions in vegetated aquatic systems. Pages 281-299 in S. S. Bell, E. D. McCoy, and H. R. Mushinsky, editors. Habitat structure: the physical arrangement of objects in space. Chapman and Hall, New York, New York, USA.

Herrnkind, W. F., J. Vanderwalker, and L. Barr. 1975. Population dynamics, ecology, and behavior of spiny lobsters, Panulirus argus, off St. Johns, U.S. Virgin Islands. IV. Habitation, patterns of movement and general behavior. Bulletin of Natural History Museum, Los Angeles 20:31-45.

Hicks, G. R. F. 1986. Meiofauna associated with rocky shore algae. Pages 36-56 in P. G. Moore and R. Seed, editors. The ecology of rocky coasts: essays presented to J. R. Lewis. Columbia University Press, New York, New York, USA.

Huffaker, C. B. 1958. Experimental studies on predation: dispersion factors and predator-prey oscillations. Hilgardia 27:343-383.

Kanciruk, P. 1980. Ecology of juvenile and adult Palinuridae (spiny lobsters). Pages 59-967 in J. S. Cobb and B. F. Phillips, editors. The biology and management of lobsters. Volume 2. Ecology and management. Academic Press, New York, New York, USA.

Lazarus, J. 1979. The early warning function of flocking in birds: an experimental study. Animal Behaviour 27:855865.

Lima, S. L., and L. M. Dill. 1990. Behavioral decisions made under risk of predation: a review and prospectus. Canadian Journal of Zoology 68:619-640.

Lipcius, R. N., and W. F. Herrnkind. 1982. Molt cycle alterations in behavior, feeding and diel rhythms of a decapod crustacean, the spiny lobster Panulirus argus. Marine Biology 68:241-252.

MacDonald, C. D., S. C. Jazwinski, and J. H. Prescott. 1984. Queuing behavior of the Hawaiian spiny lobster, Panulirus marginatus. Bulletin of Marine Science 35:111-114.

Magurran, A. E., and S. I. Girling. 1986. Predator model recognition and response habituation in shoaling minnows. Animal Behaviour 34:510-518.

Mangel, M., and C. W. Clark. 1988. Dynamic modeling in behavioral ecology. Monographs in behavior and ecology. Princeton University Press, Princeton, New Jersey, USA.

Miller, D. L. 1989. The evolution of Mexico's Caribbean spiny lobster fishery. Pages 185-198 in F. Barkes, editor.
Common propery resources: ecology and community-based sustainable development. Valhaven Press, London, England.

Mittlebach, G. G. 1988. Competition among refuging sunfishes and effects of fish density on littoral zone invertebrates. Ecology 69:614-623.

Moran, D. P., and M. L. Reaka. 1988. Bioerosion and the availability of shelter for benthic reef organisms. Marine Ecology Progress Series 44:249-263.

O'Conner, N. A. 1991. The effects of habitat complexity on the macroinvertebrates colonising wood substrates in a lowland stream. Oecologia (Berlin) 85:504-512.

Phillips, B. F. 1990. Estimating the density and mortality of juvenile western rock lobsters (Panulirus cygnus) in nursery reefs. Canadian Journal of Fisheries and Aquatic Sciences 47:1330-1338.

Pitcher, T. J., D. A. Green, and A. E. Magurran. 1986. Dicing with death: predator inspection behavior in minnow shoals. Journal of Fish Biology 28:439-448.

Pulliam, H. R. 1989. Individual behavior and the procurement of essential resources. Pages 25-38 in J. Roughgarden, R. M. May, and S. A. Levin, editors. Perspectives in ecological theory. Princeton University Press, Princeton, New Jersey, USA.

Pulliam, H. R., and T. Caraco. 1984. Living in groups: is there an optimal group size? Pages 122-147 in J. R. Krebs and N. B. Davies, editors. Behavioural ecology: an evolutionary approach. Second edition. Blackwell Scientific, Oxford, United Kingdom.

Ryer, C. H. 1988. Pipefish foraging: effects of fish size, prey size and altered habitat complexity. Marine Ecology Progress Series 48:37-45.

Schneider, F. I., and K. H. Mann. 1991. Species specific relationships of invertebrates to vegetation in a seagrass bed. I. Correlational studies. Journal of Experimental Marine Biology and Ecology 145:101-117.

Shulman, M. J. 1985. Recruitment of coral reef fishes: effects of distribution of predators and shelter. Ecology 66:10561066.

Siegfried, W. R., and L. G. Underhill. 1975. Flocking as an antipredator strategy in doves. Animal Behaviour 23:504508.

Sih, A. 1982. Foraging strategies and the avoidance of predation by an aquatic insect, Notonecta hoffmanni. Ecology 63:786-796.

- 1986. Antipredator responses and the perception of danger by mosquito larvae. Ecology 67:434-441.

Sloan, N. A., C. P. Lauridsen, and R. M. Harbo. 1987. Recruitment characteristics of the commercially harvested red sea urchin Strongylocentrotus franciscanus in southern British Columbia. Fisheries Research 5:55-69.

Smith, F. E. 1972. Spatial heterogeneity, stability, and diversity in ecosystems. Transactions of the Connecticut Academy of Arts and Sciences 44:309-355.

Smith, K. N. 1990. Relative predation on behaviorally distinct size classes of juvenile Caribbean spiny lobster, Panulirus argus. Thesis, Florida State University, Tallahassee, Florida, USA.

Sokal, R. R., and F. J. Rohlf. 1981. Biometry. W. H. Freeman, New York, New York, USA.

Steger, R. 1987. Effects of refuges and recruitment on gonodactylid stomatopods, a guild of mobile prey. Ecology 68 : 1520-1533.

Tegner, M. J., and P. K. Dayton. 1977. Sea urchin recruitment patterns and implications of commercial fishing. Science 196:324-326.

Underwood, A. J. 1981. Techniques of analysis of variance in experimental marine biology and ecology. Oceanography and Marine Biology Annual Review 19:513-605.

Werner, E. E., J. F. Gilliam, D. J. Hall, and G. G. Mittlebach. 
1983. An experimental test of the effects of predation risk on habitat use in fish. Ecology 64:1540-1548.

Wiens, J. A. 1976. Population responses to patchy environments. Annual Review of Ecology and Systematics 7: 81-120.

Winer, B. J. 1971. Statistical principles in experimental design. Second edition. McGraw Hill, New York, New York, USA.

Zar, J. H. 1984. Biostatistical analysis. Second edition. Prentice-Hall, Englewood Cliffs, New Jersey, USA.
Zimmer-Faust, R. K., and E. Spanier. 1987. Gregariousness and sociality in spiny lobsters: implications for den habitation. Journal of Experimental Marine Biology and Ecology 105:57-71.

Zimmer-Faust, R. K., J. E. Tyre, and J. F. Case. 1985. Chemical attraction causing aggregation in the spiny lobster, Panulirus interruptus, and its probable ecological significance. Biological Bulletin (Woods Hole) 169:106-1 18. 